\title{
Moisture transport by Atlantic tropical cyclones onto the North American continent
}

\author{
Guangzhi Xu1 ${ }^{1}$ - Timothy J. Osborn ${ }^{1} \cdot$ Adrian J. Matthews $^{2}$
}

Received: 22 January 2016 / Accepted: 23 June 2016 / Published online: 6 July 2016

(C) The Author(s) 2016. This article is published with open access at Springerlink.com

\begin{abstract}
Tropical Cyclones (TCs) are an important source of freshwater for the North American continent. Many studies have tried to estimate this contribution by identifying TC-induced precipitation events, but few have explicitly diagnosed the moisture fluxes across continental boundaries. We design a set of attribution schemes to isolate the column-integrated moisture fluxes that are directly associated with TCs and to quantify the flux onto the North American Continent due to TCs. Averaged over the 2004-2012 hurricane seasons and integrated over the western, southern and eastern coasts of North America, the seven schemes attribute 7-18\% (mean $14 \%$ ) of total net onshore flux to Atlantic TCs. A reduced contribution of $10 \%$ (range 9-11\%) was found for the 1980-2003 period, though only two schemes could be applied to this earlier period. Over the whole 1980-2012 period, a further $8 \%$ (range 6-9\% from two schemes) was attributed to East Pacific TCs, resulting in a total TC contribution of $19 \%$ (range 17-22\%) to the ocean-to-land moisture transport onto the North American continent between May and November. Analysis of the attribution uncertainties suggests that incorporating details of individual TC size and
\end{abstract}

Guangzhi Xu

guang.xu@uea.ac.uk

Timothy J. Osborn

T.Osborn@uea.ac.uk

Adrian J. Matthews

A.j.Matthews@uea.ac.uk

1 Climatic Research Unit, School of Environmental Sciences, University of East Anglia, Norwich, UK

2 Centre for Ocean and Atmospheric Sciences, School of Environmental Sciences and School of Mathematics, University of East Anglia, Norwich, UK shape adds limited value to a fixed radius approach and TC positional errors in the ERA-Interim reanalysis do not affect the results significantly, but biases in peak wind speeds and TC sizes may lead to underestimates of moisture transport. The interannual variability does not appear to be strongly related to the El Niño-Southern Oscillation phenomenon.

Keywords Tropical cyclone · Moisture transports · Hydrological cycle

\section{Introduction}

Tropical cyclones (TCs, including tropical depressions, storms and hurricanes) are powerful regional scale meteorological phenomena that are known for their extreme wind, intense rainfall and often very costly economical and societal losses. Despite their destructive potential, TCs also serve as an important source of freshwater and carry a considerable amount of water from ocean to land, which plays an important role in modulating regional scale droughts. Using the Palmer drought severity index (PDSI) and daily rainfall records from the Cooperative Observer Network, Maxwell et al. (2012) suggested that up to $41 \%$ of droughts over the southeastern United states during 1950-2008 were terminated by single TCs, thus the term "drought busters" was coined. During the dry years of 2006-2007, TCrelated rainfall redressed the meteorological drought over the Atlantic Coastal Plain by $20-40 \%$, and the water deficit was reduced by $50-90 \%$ in the Carolinas watersheds (Brun and Barros 2014). And for a dry continent like Australia, TC rainfall is regarded as a significant contributor to freshwater supplies for human communities, agriculture and the health of ecosystems (Dare et al. 2012). 
Some studies have documented the contribution of TCs to rainfall at a regional (e.g. Rodgers et al. 2001; Larson et al. 2005; Ren et al. 2006; Brun and Barros 2014; Konrad et al. 2002; Konrad and Perry 2009; Knight and Davis 2007, 2009; Prat and Nelson 2013; Dare et al. 2012) or global (e.g. Jiang and Zipser 2010) scale. However, few studies have looked into the effects of TCs on continental scale onshore moisture transport, which helps set up a favorable environment for precipitation. Schumacher and Galarneau (2012) quantified the moisture transported ahead of two recurving TCs (Erin in 2007 and Ike in 2008), by contrasting ensemble members from the THORPEX Interactive Grand Global Ensemble (TIGGE) where the TC recurved with those that did not. The results indicated that although being positively related, the tropical moisture transported by TCs is neither a strictly necessary nor a sufficient condition for the coincident heavy rainfalls. This illustrates the importance of a better quantification of this moisture transport, and a better understanding of its ultimate effect on precipitation. From a large scale water and energy budget point of view, TCs serve as an important balancing mechanism in redistributing tropical water and heat poleward. However, an accurate quantification of this aggregated role has not previously been made (Hart et al. 2007).

In view of such a gap, this study develops a set of methods to isolate the TC-related moisture transport from ocean to land. The column integrated moisture fluxes are estimated from the European Centre for Medium Range Weather Forecast (ECMWF) ERA-Interim (ERA-I) reanalysis product (Dee et al. 2011). The best track observations from the National Hurricane Center (NHC) (Landsea and Franklin 2013) are used to track the TCs. To make the TC moisture flux attribution, a set of distance-based attribution methods is developed. Similar distance-based methods are commonly adopted by precipitation-focused studies, where precipitation events within a certain radius of a TC are attributed to the TC's influence. Note that this kind of distance-based method in general is variable dependent: the necessary geographical vicinity for an effect to be experienced may vary from variable to variable. A typical choice among precipitation attribution studies is $500 \mathrm{~km}$ (e.g. Rodgers et al. 2001; Larson et al. 2005; Lau et al. 2008; Jiang and Zipser 2010). This provides helpful guidance to the spatial extent of TCs' influence on moisture fluxes, but should not be adopted directly without validation.

Section 2 describes the datasets and the TC flux attribution methods. Four different schemes, differing in their flexibility and adaptibility, are designed to determine a critical TC influence radius. Section 3 displays the results of applying the attribution schemes to onshore moisture fluxes, by firstly giving an overview of TC activities
(Sect. 3.1), followed by evaluations on two sample coastal grid cells (Sect. 3.2). Then the distrubtion, seasonal totals and inter-annual variabilities of TC moisture transport are presented in Sects. 3.3-3.5. When analyzing the attribution schemes and the sensitivity of TC transport to scheme selection, we consider only Atlantic TCs using a single best track dataset. The discussion of the western coast of the North American continent, which is more affected by TCs from the East Pacific, is introduced in Sect. 3.5, combining two best track datasets and using a subset of the attribution schemes. Finally, Sect. 4 assesses the uncertainties in the estimates and their relationship with ENSO.

\section{Data and methods}

\subsection{Best track TC records}

The best track records of North Atlantic tropical cyclones are obtained from the HURDAT2 (HURricane DATa 2nd generation) dataset (Landsea and Franklin 2013). This dataset is a re-analysis effort to extend and revise the NHC's North Atlantic hurricane dataset (HURDAT). Additional information is added onto the original HURDAT format, including wind radii estimates that provide information on the shape and size of a cyclone (Landsea and Franklin 2013). This radii information is used to design TC attribution schemes.

Best track records of East Pacific (EP) tropical cyclones are obtained from IBTrACS (International Best Track Archive for Climate Stewardship) (Knapp et al. 2010), which is an objective combination of best track records from various regional data centers. The inclusion of East Pacific TCs gives a more complete view of the continental freshwater inputs from TCs. However, the lack of wind radii data from IBTrACS restricts application of attribution schemes that are based on TC size observations (more on this in Sect. 2.3), and this study focuses mostly on Atlantic TCs.

\subsection{Horizontal moisture fluxes}

Humidity $(q)$ and horizontal winds ( $u$ and $v$ ) during 1979 Jan-2012 Dec are obtained from ERA-I reanalysis on a $0.75^{\circ} \times 0.75^{\circ}$ grid every $6 \mathrm{~h}$ (at $0000,0600,1200$ and 1800 UTC). Moisture fluxes on model levels 1-60 are vertically integrated to form the column moisture fluxes:

$\left\{\begin{array}{l}F_{u}=\frac{1}{g} \int_{P_{1}}^{P_{60}} u q d P \\ F_{v}=\frac{1}{g} \int_{P_{1}}^{P_{60}} v q d P\end{array}\right.$

where $d P$ is the pressure increment between model levels. 


\subsection{TC-flux attribution}

The isolation of the moisture fluxes carried by a TC from the background flow in which the TC is embedded is nontrivial and an unambiguous separation is not normally attainable. Hence, the TC-related moisture flux is defined following three main principles:

1. The TC-induced moisture flux is distinct from both the mean annual cycle and the slowly-varying background flow in the flux anomalies.

2. The spatial extent of the influence from a TC is a confined area following the movement of the TC, centered around the TC center, but not necessarily symmetrical in the four quadrants (NE, NW, SW and SE).

3. The temporal extent of the TC influence is limited to the lifetime of a TC, precedent or aftermath effects are not included.

Based on these principles we devised a set of distancebased TC-attribution schemes that use the distance from TC centers as the major decisive threshold, but also take the underlying variability of moisture fluxes into consideration.

A sequence of coastal boxes are first selected from ERA-I's land-sea-mask, (blue boxes in Fig. 2). With the $0.75 \times 0.75^{\circ}$ horizontal resolution of ERA-I, a grid box has a typical length of $70 \mathrm{~km}$ at this latitude, and a total of 276 coastal grid boxes are identified.

From HURDAT2 the TC events (hurricanes and storms) in the study region $\left(15-55^{\circ} \mathrm{N}, 40-130^{\circ} \mathrm{W}\right)$ that reached storm intensity (maximum sustained wind speed reaching 34 knot or above) at some point in their life time are selected (including the records after extra-tropical transition). Following the movement of each TC, coastal grid boxes that are within a certain threshold radius are regarded as affected by the TC (or TCs if more than one is present). The TC-affected fluxes are then calculated at these grid boxes. Whenever a non-synoptic hour in HURDAT2 (usually at times of landfalling or maximum intensity) is encountered, an additional record is inserted into the ERA-I fluxes via linear interpolation between the synoptic hours that encompass that time point.

To implement the first principle, the TC-related flux is detected from the column integrated zonal $\left(F_{u}^{\prime}\right)$ and meridional $\left(F_{v}^{\prime}\right)$ flux anomalies, which are obtained by subtracting the 1979-2012 annual cycle (the 34-year average of each 6-hourly flux value). A background anomaly flux timeseries $\left(F_{u b}^{\prime}\right.$ and $\left.F_{v b}^{\prime}\right)$ is estimated by taking the timeseries of flux anomalies at a grid cell, replacing the TC-affected time points by zero anomalies, and applying a low-pass filter. The filter used is a Gaussian-weighted filter such that the amplitude of variations on 21-day timescales is reduced by half, while faster variations are reduced much more and slower variations much less:
$\left\{\begin{array}{l}F_{u b}^{\prime}(t)=F_{u 0}^{\prime}(t) * g(t ; \sigma) \\ F_{v b}^{\prime}(t)=F_{v 0}^{\prime}(t) * g(t ; \sigma)\end{array}\right.$

where $F_{u 0}^{\prime}$ and $F_{v 0}^{\prime}$ are the 0 -replaced flux anomalies, $g(t ; \sigma)$ is the Gaussian kernel to be convolved with. The scale parameter $\sigma$ is determined using:

$\sigma=T_{1 / 2} \sqrt{\frac{\ln 2}{2 \pi^{2}}}$

where $T_{1 / 2}$ is the period at which the response amplitude is reduced by $50 \%$, which in this case is set to 21 days, a choice that covers the lifetime of the majority of Atlantic TCs (Bengtsson et al. 2007).

After subtracting the background flux, the TC-related moisture flux is defined as the residual flux when a TC is nearby within a certain radius. Distances are computed as the great-circle distances, and four different schemes (Table 1) are explored to define this critical radius:

1. Scheme 1: Fixed radius in the NW, NE, SE and SW quadrants. Four distance thresholds were tried to test the sensitivity of the results: $300,500,700$ and $900 \mathrm{~km}$.

2. Scheme 2: The maximum $34 \mathrm{kt}$ wind radius in all four quadrants through the life time of a TC, scaled by a scaling factor. Three scaling factors were considered in the sensitivity test: 2.0, 3.0, and 4.0.

3. Scheme 3: The maximum $34 \mathrm{kt}$ wind radius in the corresonding quadrant through the lifetime of a TC, scaled by a scaling factor of 3.0. For example, if a coastal grid box is to the NW of the TC center, then the critical radius is 3 times the maximum $34 \mathrm{kt}$ wind radius in the NW quadrant.

4. Scheme 4: The $34 \mathrm{kt}$ wind radius in the corresonding quadrant at the corresonding time, scaled by a scaling factor of 3.0. For example, if a coastal grid box is to the $\mathrm{NE}$ of the TC center, then the critical radius is 3 times the NE $34 \mathrm{kt}$ wind radius of the $\mathrm{TC}$ at that time point.

Going from Scheme 1 to 4 , greater degrees of flexibility and adaptibility are incorporated: Scheme 1 applies a fixed radius to all TCs regardless of their differences in size, shape and temporal evolutions. The use of wind radii (the distance from the TC center where wind speeds remain at $34 \mathrm{kt}$ or above) from HURDAT2 best track data provides an observational basis for the radius definition that can vary according to the maximum size reached by each TC (Scheme 2). Scheme 3 extends this with quadrant dependency to account for shape asymmetry of TCs. Scheme 4 is the most dynamic of all and allows the critical radius to change over the lifetime of the TC according to observations.

Note that the wind radii data from HURDAT2 are only available from 2004 onwards, during which missing values may be present, in which case a backward relaxation 
scheme is implemented: in Scheme 4 if the wind radius in a given quadrant at a given time is missing, relax back to the maximum of the corresonding quadrant (Scheme 3). If all values in a quadrant are missing, relax back to the four-quadrant maximum (Scheme 2). There is no simple relationship between the size and central minimal pressure of TCs (Emanuel 2005; Knaff et al. 2007; Knaff and Zehr 2007; Ren et al. 2007), therefore we did not attempt to predict the wind radii to extend Schemes $2-4$ back in time. Analysis using Scheme 1 is extended back to 1980. Similar analysis using Scheme 1 is also performed on TCs from the East Pacific, based on best tracks from IBTrACS, for the period of 1980-2012.

\section{Results}

\subsection{Overview of TC activities}

Figure 1 displays the tracks of all Atlantic and East Pacific TCs during May-Nov that came within $700 \mathrm{~km}$ of the

(a) 1980 - 1990

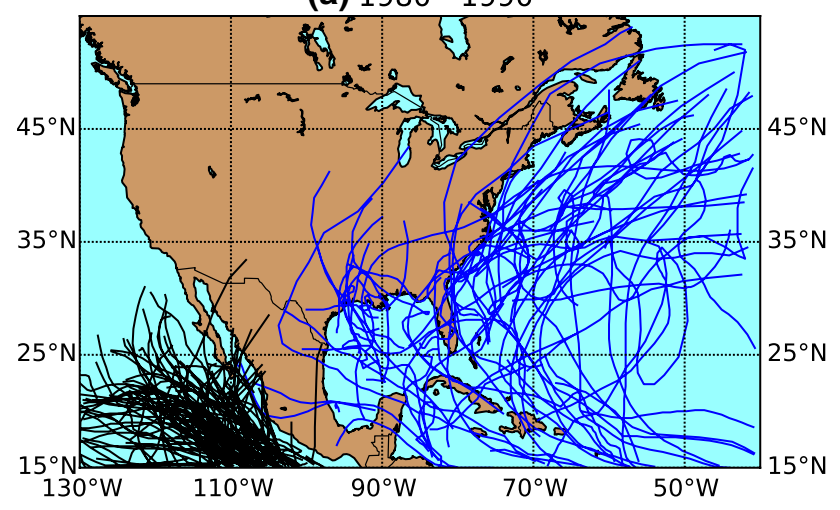

(c) $2001-2012$

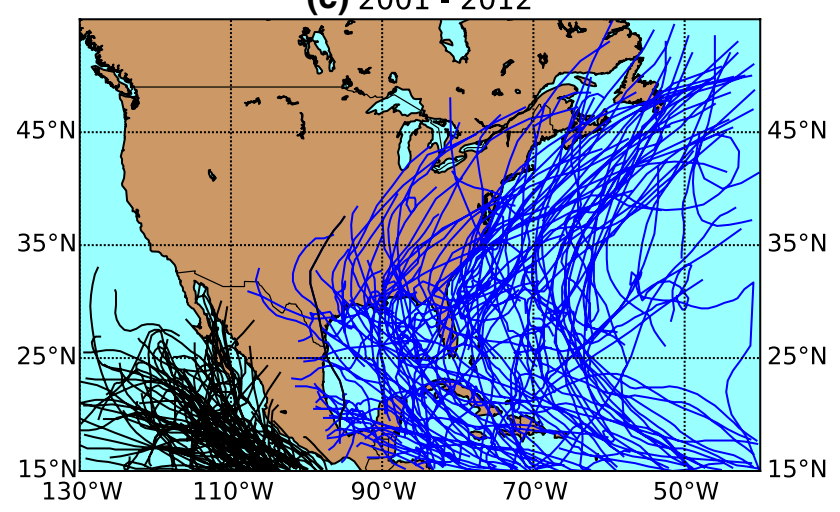

Fig. 1 TC tracks from the Atlantic (blue) and East Pacific (black) during a 1980-1990, b 1991-2000 and c 2001-2012 that reached storm intensity (maximum sustained surface wind $\geq 34 \mathrm{kt}$ ) within the
North American continent in each of three 10- or 11-year periods during 1980-2012. These TCs are selected from a subset that ever reached storm intensity (maximum sustained surface wind $\geq 34 \mathrm{kt}$ ) within the study region. There are broadly two preferred pathways of Atlantic TCs, one into the Gulf of Mexico from the Caribbean Sea and the other along the Gulf stream with a recurvature northeastward (see also Konrad and Perry 2009). Many of the TCs that follow the latter path or off the western coast did not make landfall but rather grazed the coastline at some distance; whether these TCs will be regarded as relevant to onshore transport depends on the attribution scheme selected, their sizes and the distances offshore. Based on the TC occurrences the coastal lines of North America can be divided into three sections: the western coast, Gulf of Mexico and the eastern coast (detailed definition will be introduced later). The Greater Antilles islands are buried in the TC tracks and can experience impacts from both pathways. These grid boxes are treated as a fourth section, although estimates of these TC fluxes may have larger errors due to the coarse resolution.

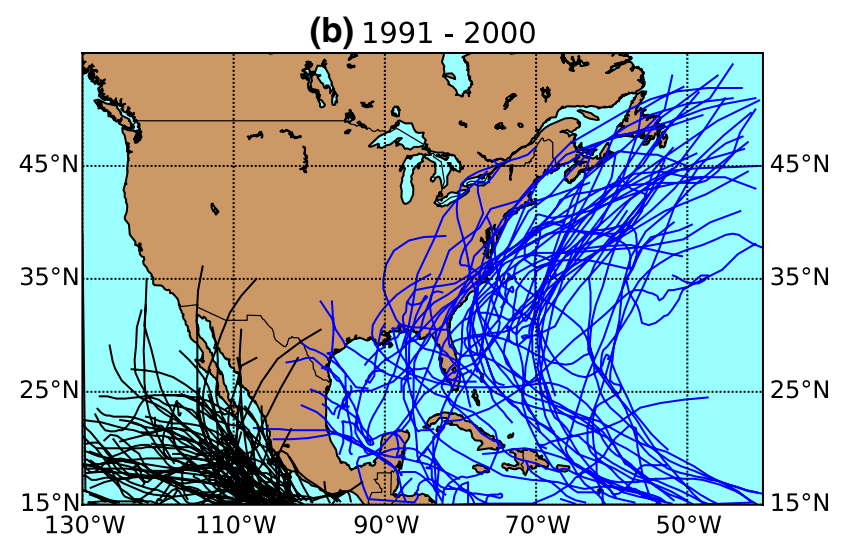

(d)

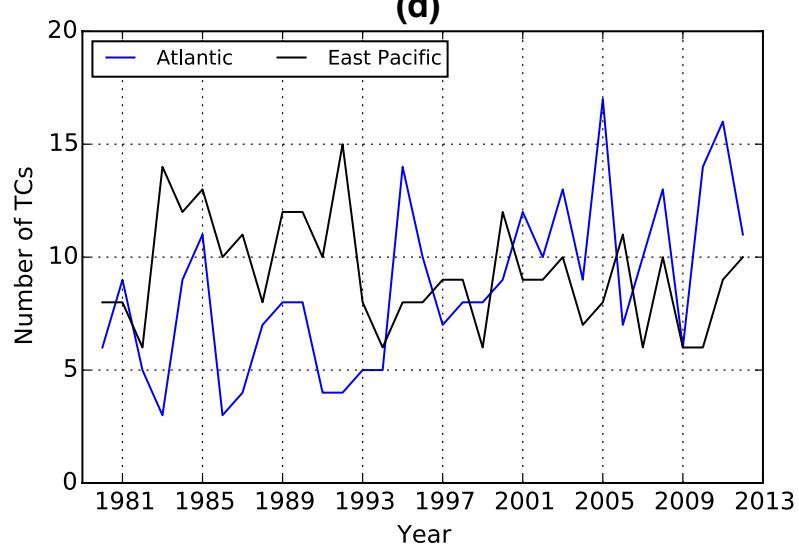

study region and came within $700 \mathrm{~km}$ of the North American coast. d The number of Atlantic (blue) and East Pacific (black) TCs identified using the above criteria in May-Nov each year 
(a) Centers of RITA in best track and ERA-I
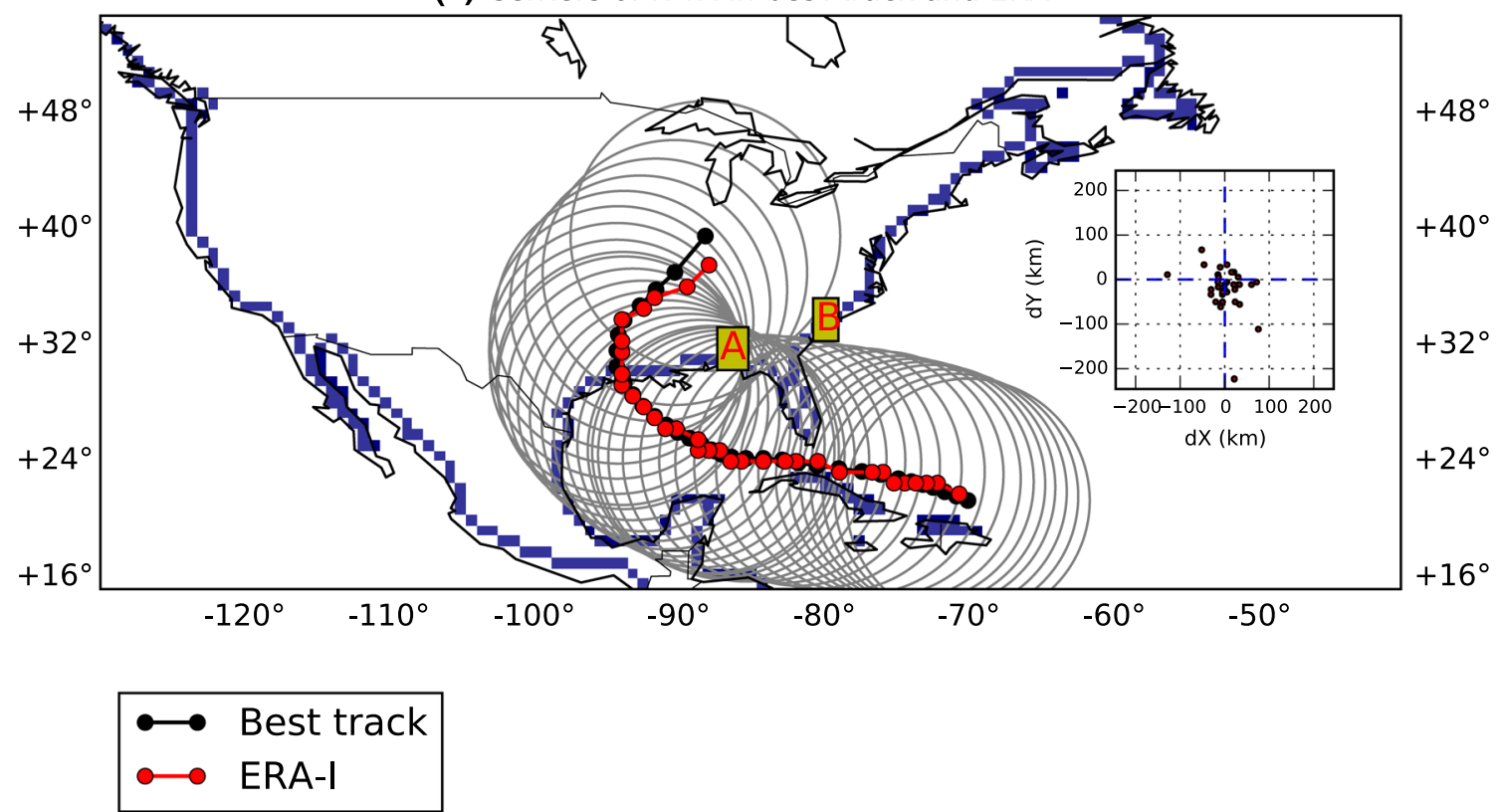

(b) Centers of KATRINA in best track and ERA-I

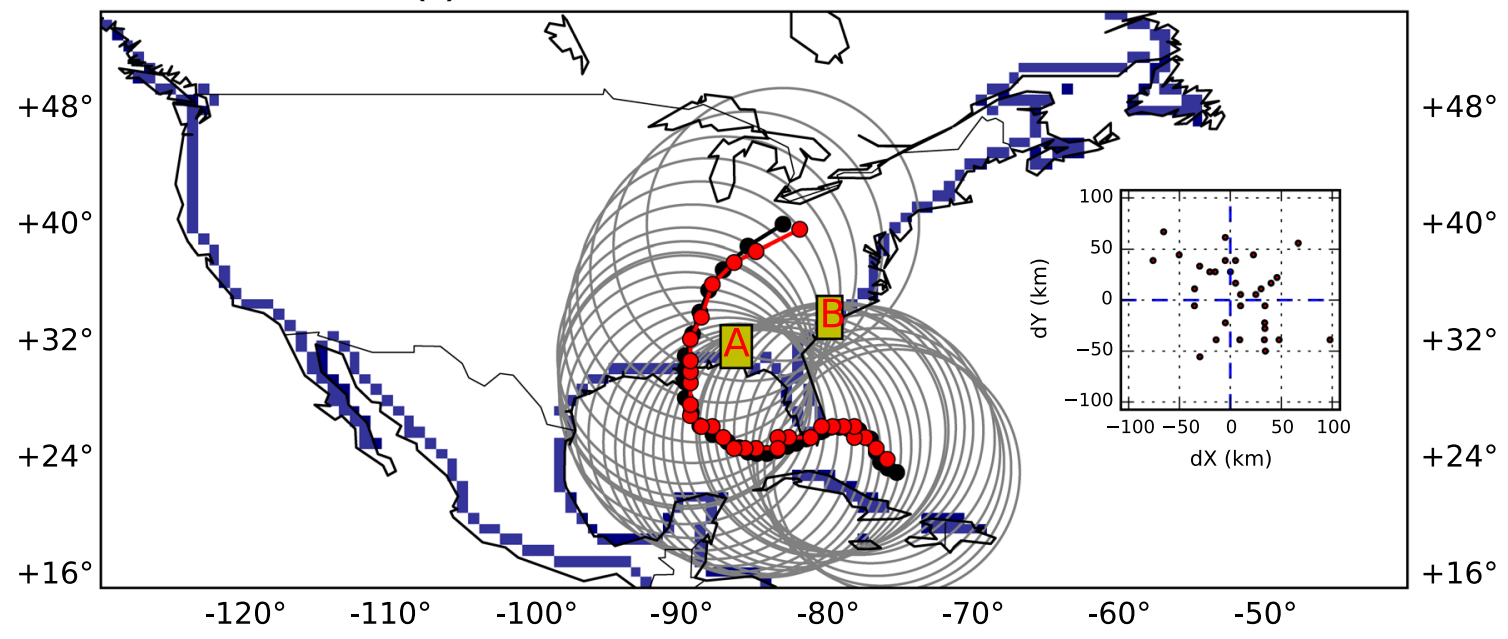

Fig. 2 Coastal grid boxes of the North American continent and sample TC tracks. The coastal boxes defined from ERA-I land-seamask in the study region are plotted out in blue. The best track locations of TC Rita are plotted in black in (a) and Katrina in (b), both events occurred in 2005. The corresponding TC centers detected from relative vorticity maxima (at model level 48) using a Difference

Increased Atlantic TC activities can be observed from the track plots in Fig. 1 as well as the TC number timeseries in Fig. 1d. The year 1994 separates a relatively quiescent decade before and an active decade after that, reflecting the Atlantic multi-decadal mode (Goldenberg 2001). Conversely, East Pacific TC activity displays largely opposite long-term changes: stronger before 1994 and weaker afterwards. On top of that, strong inter-annual variability can be observed, largely consistent with that found by Nogueira and Keim (2011). of Gaussians blob detection algorithm are plotted in red. A $900 \mathrm{~km}$ fixed radius circle is plotted following the movement of best track TC centers. The inset plots display the differences (in $\mathrm{km}$ ) between the best track and blob detected TC centers, by centering the former at the origin. Two sample grid boxes are labelled on the map: A $\left(31.0^{\circ} \mathrm{N}, 87.0^{\circ} \mathrm{W}\right)$ and $\mathrm{B}\left(33.0^{\circ} \mathrm{N}, 80.4^{\circ} \mathrm{W}\right)$

Figure 2 displays the tracks of two major hurricanes: Rita and Katrina in 2005, based on best track records. For confidence in the calculated TC moisture fluxes, it is important that the TC locations from best track and ERA-I are consistent. To evaluate the positional difference between the two, we detected TC centers from ERA-I for these two TCs. The detection only takes into account the relative vorticity (RV) field (at model level 48, approximately $840 \mathrm{hPa}$ ) and locates RV maxima via a difference-of-Gaussians blob 

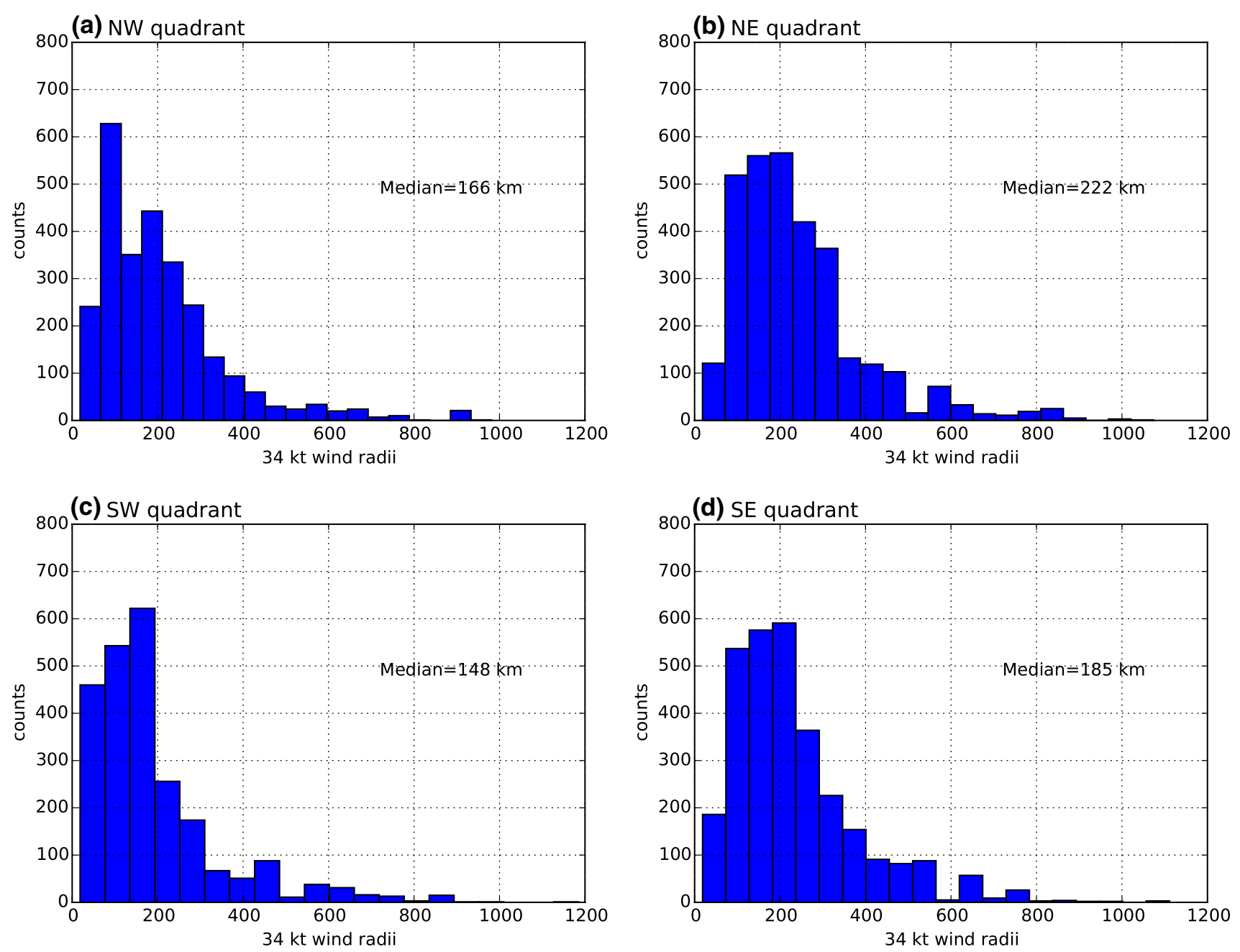

Fig. 3 TC $34 \mathrm{kt}$ wind radii distribution in four quadrants, for all Atlantic TC records within the study region of $15-55^{\circ} \mathrm{N}$, $40-130^{\circ} \mathrm{W}$ that reach storm intensity (maximum sustained wind

speed $\geq 34 \mathrm{kt}$ ) during 1980-2012. The distribution in the NW, NE, SW and SE quadrant is shown in (a), (b), (c) and (d), respectively

Table 1 TC flux attribution schemes. First column shows the detection schemes as introduced in Sect. 2.3. Second column lists the parameter, either a fixed radius for Scheme 1, or the scaling factor for Schemes 2-4. Column three indicates whether the scheme is retained for subsequent analyses

\begin{tabular}{lll}
\hline Scheme & Parameter (radii or scaling) & $\begin{array}{l}\text { Retained for subse- } \\
\text { quent analysis }\end{array}$ \\
\hline 1 & $300 \mathrm{~km}$ & No \\
1 & $500 \mathrm{~km}$ & No \\
1 & $700 \mathrm{~km}$ & Yes \\
1 & $900 \mathrm{~km}$ & Yes \\
2 & 2.0 & Yes \\
2 & 3.0 & Yes \\
2 & 4.0 & Yes \\
3 & 3.0 & Yes \\
4 & 3.0 & Yes \\
\hline
\end{tabular}

Fig. 4 Illustration of the TC flux attribution at a coastal box at $31.0^{\circ} \mathrm{N}, 87.0^{\circ} \mathrm{W}$ ( $A$ in Fig. 2). The black line shows the time series of column integrated meridional moisture flux anomalies (in $\mathrm{kg} \mathrm{m}^{-1} \mathrm{~s}^{-1}$ ) during April-Nov 2005. Red line shows the estimated background flow by applying a Gaussian filter after the TC-affected time points are replaced with zeros (using Scheme 1 with fixed $900 \mathrm{~km}$ radius). Blue (green) line is the result of a box-car (Gaussian) filtering with a kernel size of 21 days on the original time series. Each horizontal band of pink or green background shading shows a different radius definition scheme, from Scheme 1 with fixed $300 \mathrm{~km}$ radius at the top, to Scheme 4 with a scaling factor of 3.0 at the bottom. They are labelled on the figure. Within each scheme band, time points when this grid box is deemed as TC-affected are shown by dark green shading, with the relevant TC names labelled nearby

detection algorithm (Lowe 2004). The results displayed in Fig. 2 suggest a good agreement between the two, and the offsets are typically a few tens of kilometers, which is about the scale of ERA-I's horizontal resolution and 


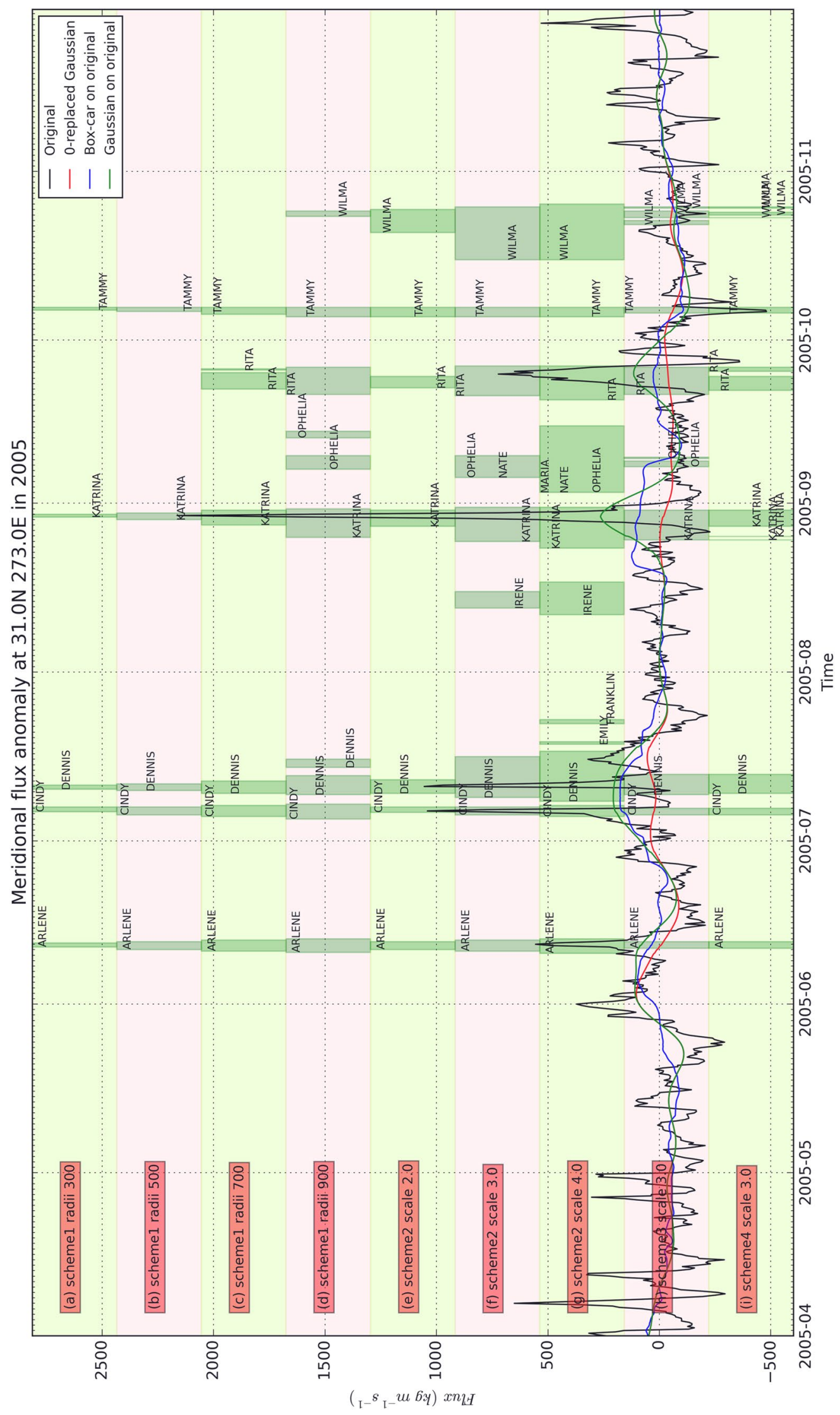


relatively small compared to a typical TC detection radius. However, offsets in earlier years could be larger (Jourdain et al. 2014).

The distribution of $34 \mathrm{kt}$ wind radii from HURDAT2, for each quadrant, is shown in Fig. 3. Consistent for all four quadrants, the distribution is highly skewed to the right, with the maximum radii reaching up to $1185 \mathrm{~km}$ in the SW quadrant. As the detecting Schemes 2 to 4 favour maximum radii (Scheme 4 may relax back onto maximum radii in cases of missing values), these large radii records can lead to far-reaching TC influencing circles. The majority of the $\mathrm{TC}$ records have a $34 \mathrm{kt}$ wind radius below $500 \mathrm{~km}$, and the median value is $166 \mathrm{~km}$ in NW, $222 \mathrm{~km}$ in NE, $148 \mathrm{~km}$ in SW and $185 \mathrm{~km}$ in SE quadrant, respectively. There is a slight shape asymmetry with the eastern quadrants stretched further than the western half, consistent with literature (Price et al. 1994; Liu and Chan 1999; Jourdain et al. 2014). Taking into account the cyclonic TC circulation and southeast-ward facing coastal line where TCs make landfall, this asymmetry may create a more extensive onshore transport branch than the offshore branch.

\subsection{TC flux attribution}

The effectiveness of TC flux attribution is first tested on two sample grid boxes: box A at $31.0^{\circ} \mathrm{N}, 87.0^{\circ} \mathrm{W}$ in the Gulf of Mexico section, and box $\mathrm{B}$ at $33.0^{\circ} \mathrm{N}, 80.4^{\circ} \mathrm{W}$ in the eastern coast section (both labelled in Fig. 2). Nine different attribution schemes are tested and the setups are listed in Table 1. The fixed radius scheme (Scheme 1) includes $300 \mathrm{~km}$ and $500 \mathrm{~km}$ radii, covering the range many precipitation attribution studies have adopted (Dare et al. 2012), and extends further to include $700 \mathrm{~km}$ and $900 \mathrm{~km}$, to cover the possibly larger response areas in wind than in precipitation. Three scaling factors are applied to Scheme 2 to test the sensitivity to symmetrical sizes. Schemes 3 and 4 with a scaling factor 3.0 are included to test the sensitivity to shape asymmetry and size evolution during a TC's lifetime.

The 2005 timeseries of meridional column-integrated moisture flux anomaly at box A is shown in Fig. 4 as the black curve. Based on Scheme 1 with a fixed $900 \mathrm{~km}$ radius (horizontal shaded band d in Fig. 4), the time points when a TC (or multiple TCs) is nearby are marked with dark green shading. Therefore the five most prominent spikes induced by TC Arlene, Cindy, Dennis, Katrina and Rita are correctly attributed. These abrupt pulses are all positive in sign, as the relevant TCs all passed to the west of box A (e.g. Katrina as shown in Fig. 2). Tammy (Oct-5 - Oct-7) induced a negative flux anomaly, as it approached the sample box from the east, before recurving south-eastwards (not shown).

With these TC-affected time points replaced with zeros, the 21-day Gaussian filter generates an estimated
Fig. 5 Same as Fig. 4 but for the zonal flux at grid box $33.0^{\circ} \mathrm{N}, 80.4^{\circ} \mathrm{W}$ ( $B$ in Fig. 2), and the estimated background flows are based on scheme 2 with scaling factor 4.0. Also note that the green line shows the low-pass by a 21-day Gaussian filter with TCaffected time points masked

background anomaly flow (red curve in Fig. 4). Also included are the estimates from a box-car filter (blue line) and the same Gaussian filter (green line) on the original anomaly time series (not zero-replaced). All three estimates are based on scheme-1-radii-900. These three filters give largely consistent estimates during the TC-free periods, but show considerable differences in the vicinity of TCs. The box-car filter creates step-like changes before and after Katrina and Rita, suggesting insufficient resilience to abrupt changes. On the other hand, were the TC-affected fluxes not replaced with zeros, the Gaussian filter also gives an unsatisfactory result (green line). It is worth noting that the estimated background flow will be different if a different detection scheme is used and so will the deviations from it that are attributed to TCs.

Despite the successful attribution of the five major TCs by the fixed $900 \mathrm{~km}$ scheme, the other two cases, Ophelia and Wilma, lack an obvious response in the flux, and therefore are likely to be false detections. This is because the fixed $900 \mathrm{~km}$ radius goes beyond the actual influencing extent of these TCs. When reduced to $700 \mathrm{~km}$ (shaded panel c in Fig. 4), the two false detections are eliminated. Further reduction in the radius starts to induce false negative errors, for instance the fixed $500 \mathrm{~km}$ (panel b) and $300 \mathrm{~km}$ (panel a) schemes fail to detect Rita, and other major TCs are detected for too short a duration.

Similarly, among the three wind radii based Scheme 2 setups (with scaling factors of 2.0, 3.0 and 4.0, correponding to panel e, $\mathrm{f}$ and $\mathrm{g}$ in Fig. 4, respectively), a large scaling factor inflates the detecting radius and tends to pick up faraway TCs whose influence can not be discerned. Such errors are evident in the scheme-2-scale-4.0 case (panel $\mathrm{g}$ ), which falsely detected a few periods when notable flux responses are lacking.

The more adaptive schemes (scheme-3-scale-3.0 in panel $\mathrm{h}$, and scheme-4-scale-3.0 in panel i) create some closely spaced narrow and intermittent bins in the TC time shading (Fig. 4). This is a combined result of the movement of the TC and time-varying detecting radius, which can be dramatic between 6-h intervals (Konrad et al. 2002). At least in this illustrated case the extra adaptibility does not provide much added value to attribution accuracy, as the underlying flux shows even more temporal coherency than the frequently alternating detecting bins. This also demonstrates the inherent deficiency of the binary, distance-based detection method in general.

Figure 5 illustrates the attribution of zonal moisture flux at grid box B. Different to box A, the green curve shows the 


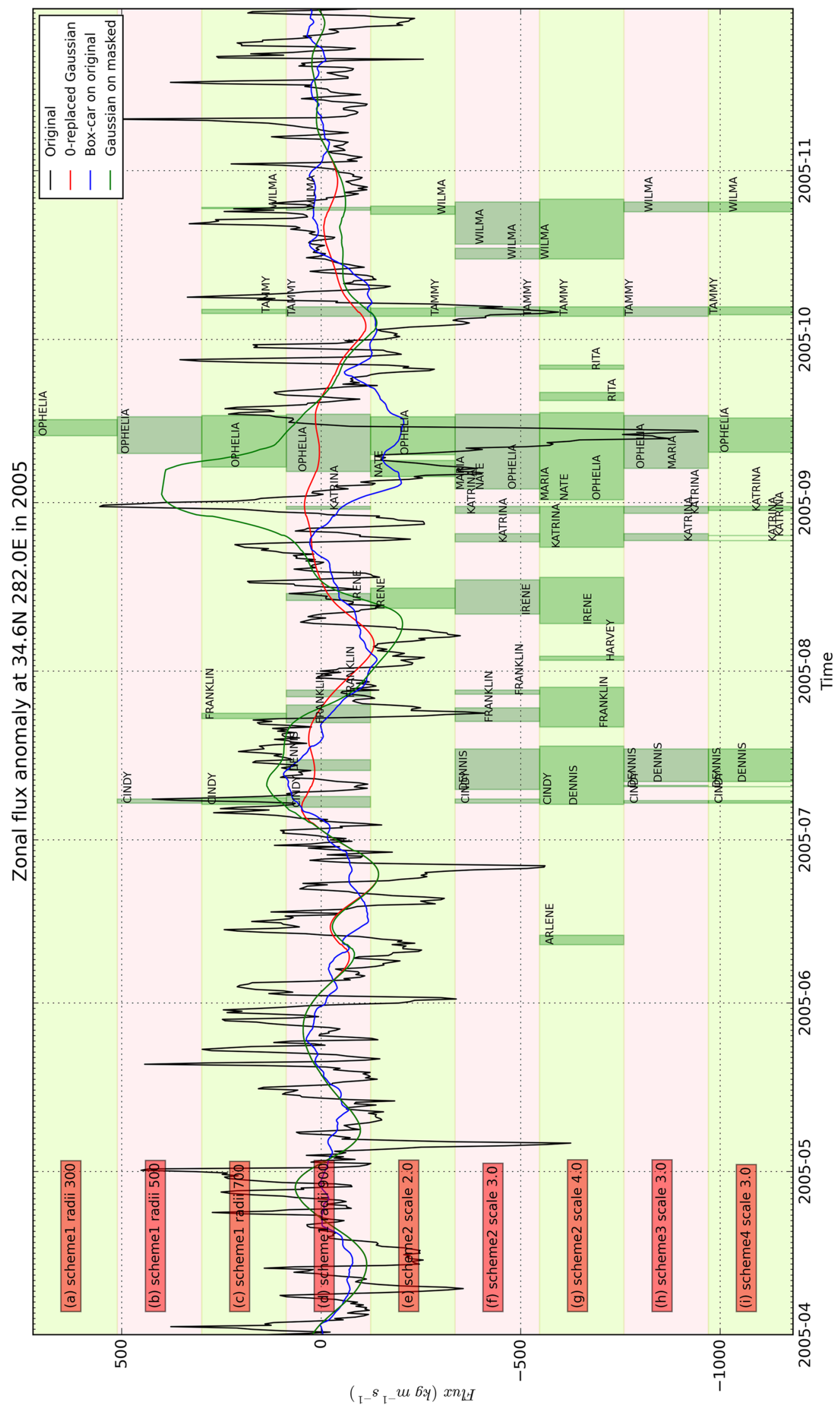


Fig. 6 Spatio-temporal distribution of Atlantic TC onshore fluxes (in $10^{8} \mathrm{~kg} \mathrm{~s}^{-1}$ ) during May-Nov 2005, using scheme1radii-900. a Gives a geographical reference of the coastal line, relevant TC tracks and their landfalling locations (if any, marked using a green triangle). The coastal boxes are numbered and ordered to represent the western coast section ( $0-92$, in green), the Gulf of Mexico section (93-166, in yellow), the eastern coast section (167-252, in orange) and the Greater Antilles section (253-275, in brown). b Shows the time-location distribution in a hovmoller plot, with TC onshore fluxes aggregated over calendar months. Horizontal solid lines indicate section boundaries, therefore the panels from top to bottom are the Greater Antilles, eastern coast, Gulf of Mexico and western coast, respectively. Landfalling locations and times are also marked (triangles) on the hovmoller plot

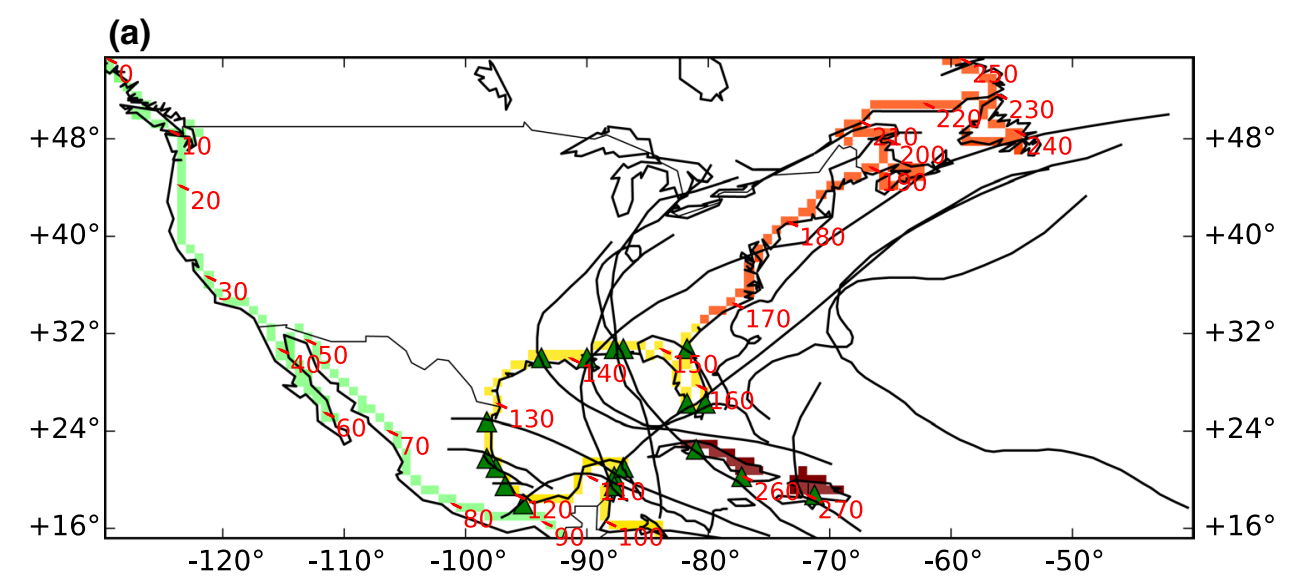

(b) Scheme: scheme1 radii 900

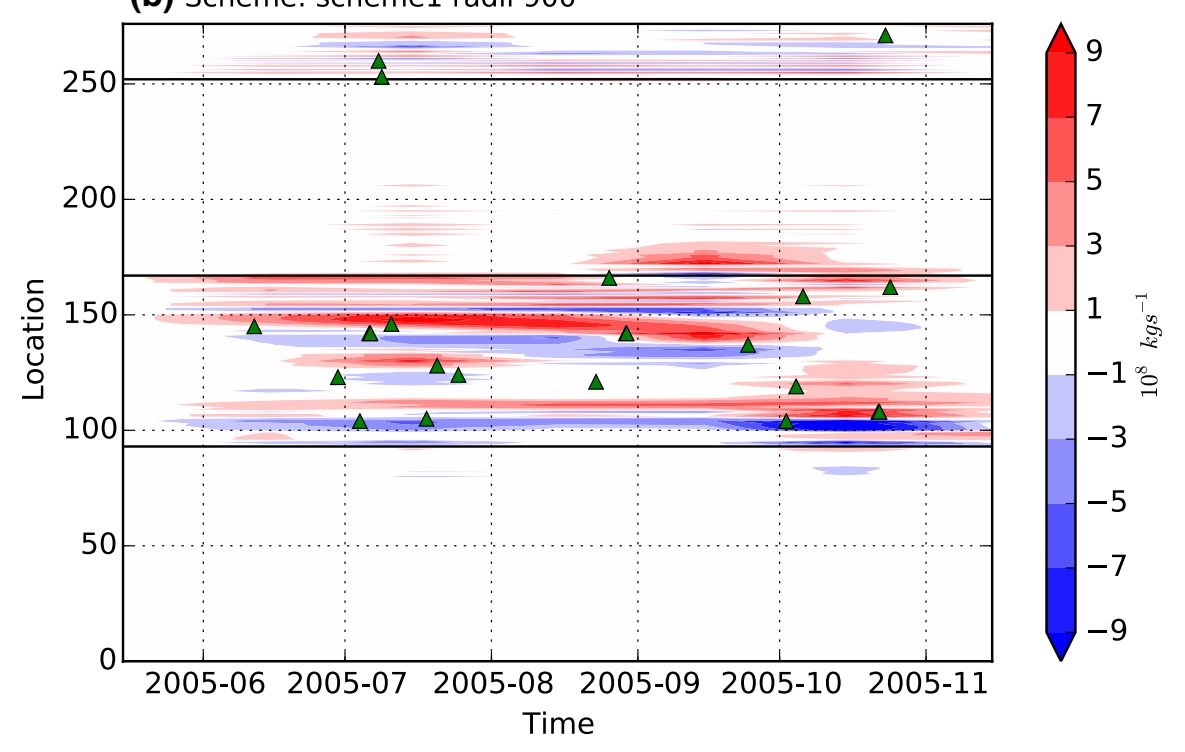

Gaussian filtered time series with the shaded TC time points treated as missing rather than set to zero, and the background flow estimates are based on Scheme 2 with scaling factor 4.0 (panel $\mathrm{g}$ in Fig. 5). Large differences are observed in the estimated background fluxes during late Aug-Sept, when the green curve shows spuriously high values, due to the 2-day gap between the masked values of Katrina and Ophelia. Notable for its erratic and slow moving track, Ophelia lingered for a long time along the eastern coast at storm and hurricane intensities. Such long-lasting effects post a challenge to background flow estimates, as can be seen in the box-car filter (blue curve). In such cases, replacing the TC time points with zeros helps create a better estimate (red curve).

Although false positive errors are found in the scheme2-scale-4.0 scheme at box A, it is able to pick up some TC impacts at box B that other schemes failed to, for instance the full extent of Franklin, Katrina and Ophelia (when Maria and Nate may also contribute). The correctness of the Irene and Rita attribution may be controversial, and the length of Wilma seems to be overestimated. However, this examination of individual grid cells is ad hoc, and fine-tuning a specific scheme may overfit the selected sample and lose generality. Therefore scheme-2-scale-4.0 is retained for subsequent analyses. But we exclude scheme-1-radii-300 and scheme-1-radii-500 from the selection, as both being too conservative. Again the highly variable scheme3-scale-3.0 and scheme-4-scale-3.0 detect intermittent TC effects during Dennis and Katrina. They seem to improve the detection accuracy compared with their symmetrical counter-part (scheme-2-scale-3.0 scheme), by eliminating Irene from detection, but the omission of Franklin and earlier part of Wilma is arguable. These two schemes are also retained in the ensemble.

It is worth noting that at both box A and B, no scheme is able to fully capture the finishing stage of Katrina (Figs. 4, 5), even for the most expansive scheme (scheme2 -scale-4.0). And in the case of Tammy the schemes do not attribute the large negative (positive) zonal anomalies 


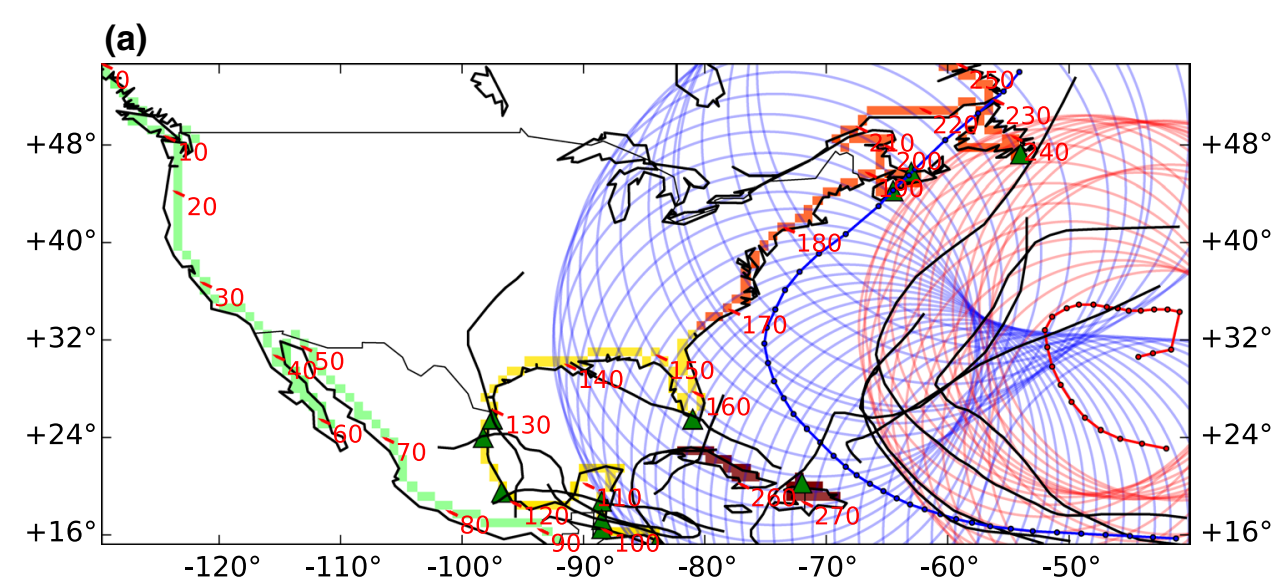

(b) Scheme: scheme2 scale 4.0

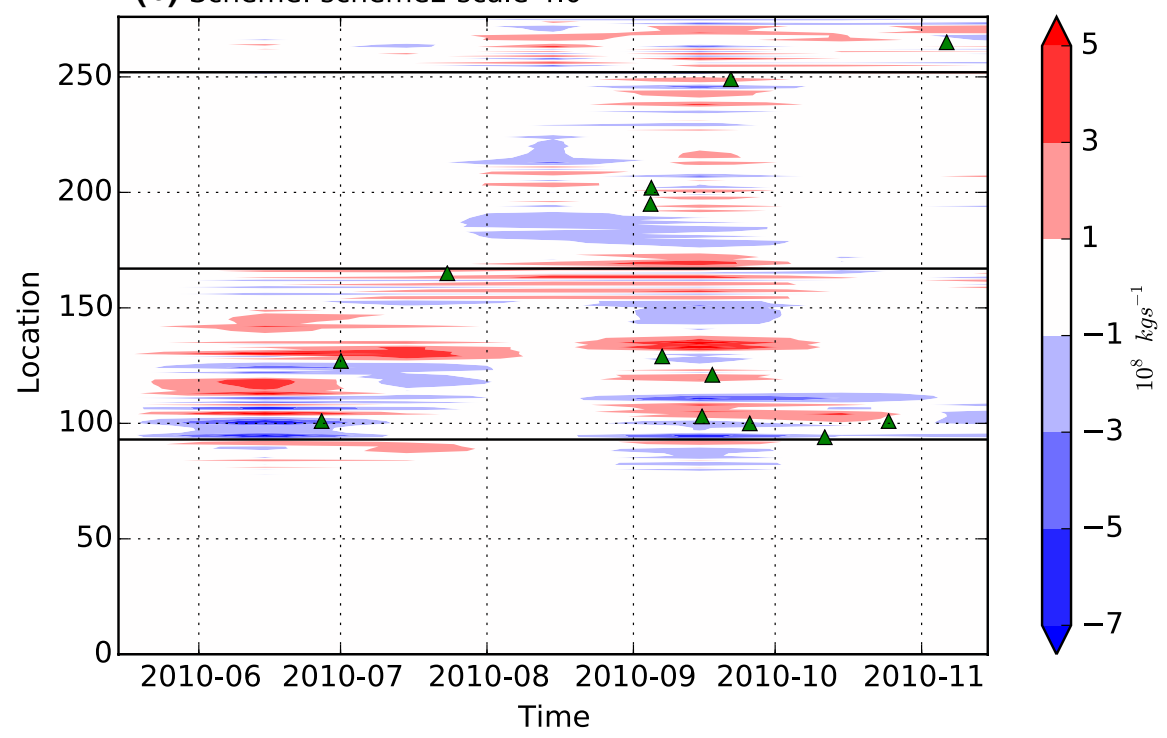

Fig. 7 Same as Fig. 6 but for year 2010 using scheme2-scale-4.0. The tracks of TC Danielle and its 2667 km radii (after scaling by 4.0 ) are plotted in red, and Igor with its $3333 \mathrm{~km}$ radii (after scaling) are plotted in blue

before (after) Oct-5 and Oct-6 (Fig. 5). This is because the lifetime of these TCs are defined by best track records, and the TC had either not existed before significant precedent flow occurred, or already died away before the strong flow anomalies dissipated. Relating back to the earlier discussion, these precedent and aftermath effects are not included and it is largely a subjective choice. However, enlarging the detection radius would be biased because the precedent effects would more likely be captured than the aftermath effects.

\subsection{Spatial distribution of TC onshore transport}

Based on the two case studies in the previous section, we included seven detection schemes in the ensemble collection (Table 1) and performed TC and non-TC flux separation for each coastal grid box using these schemes. TC-related moisture flux is defined as the difference between the full flux anomaly and the background flux anomaly during the green-shaded time points. The same separation procedure is also repeated on the immediate oceanic grid boxes, whose fluxes, together with those from the adjacent land boxes, are used to compute the mean onshore flux $F_{u}$ and $F_{v}$ by averaging the two. The onshore moisture transport is computed as:

$$
\left\{\begin{array}{l}
T_{u i}=-\mathbf{F}_{\mathbf{u i}} \cdot \mathbf{d} \mathbf{y}_{\mathbf{i}} \\
T_{v i}=-\mathbf{F}_{\mathbf{v i}} \cdot \mathbf{d} \mathbf{x}_{\mathbf{i}}
\end{array}\right.
$$

where $T_{u i}$ and $T_{v i}$ are the TC onshore transport $\left(\mathrm{kg} \mathrm{s}^{-1}\right)$ at grid box $i$ in the zonal and meridional direction, 


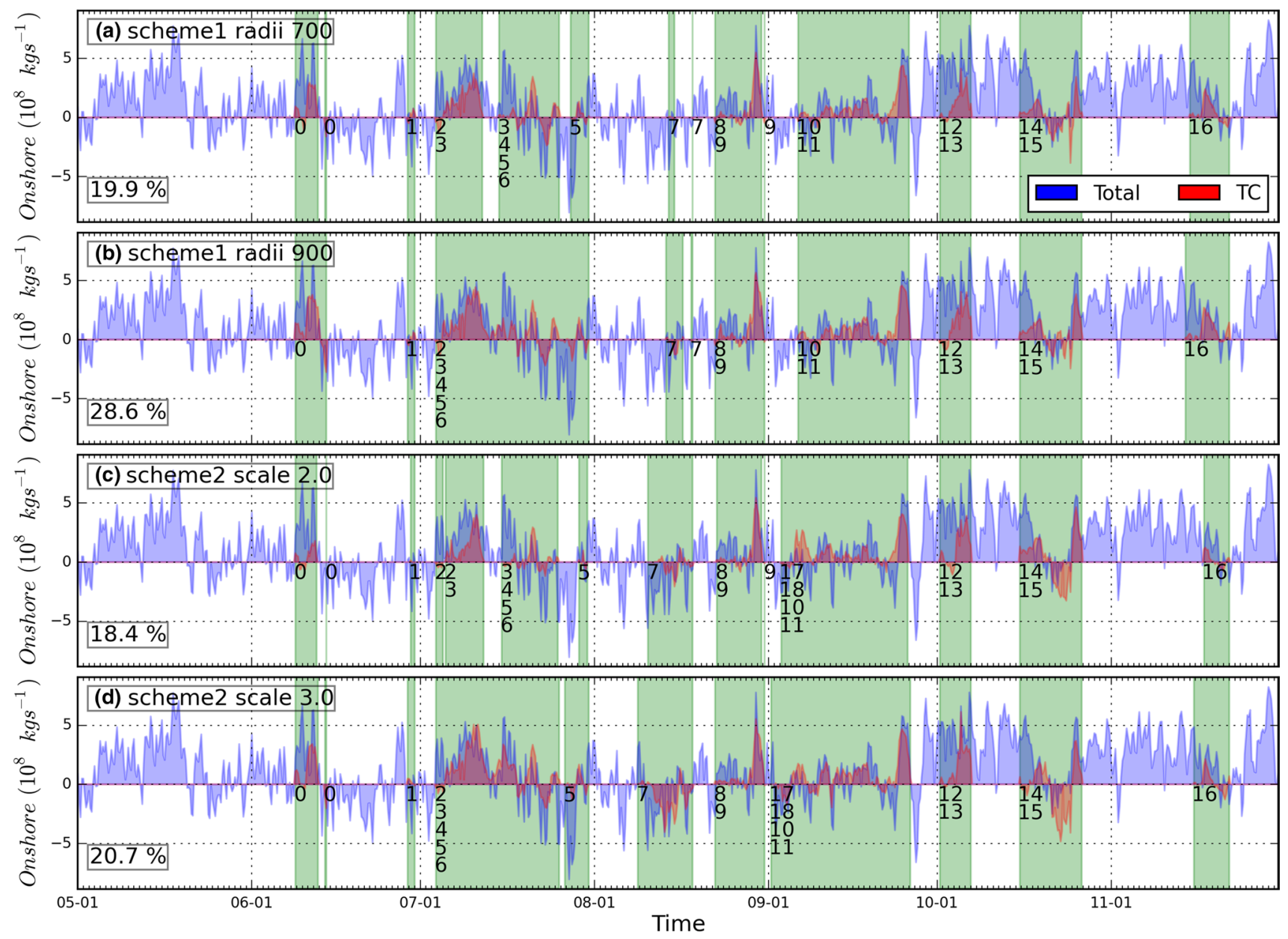

Fig. 8 Time series of the total (blue) and Atlantic TC-attributed (red) integrated onshore transport $\left(10^{8} \mathrm{~kg} \mathrm{~s}^{-1}\right)$ during May-Nov 2005, by TCs under a scheme-1-radii-700, b scheme-1-radii-900, c scheme2-scale-2.0, d scheme-2-scale-3.0 (see Table 1 for the schemes). The total moisture transport combines the annual cycle and anom- aly fluxes. Time periods when any coastal grid boxes are affected by TCs are indicated by green shading, to which a numerical ID is attached for each relevant TC (the ID-name translation can be found in Table 2). The percentage contribution by TCs to the total transport is labelled at the lower left corner for each scheme respectively. $\mathbf{d y}_{\mathbf{i}}$ and $\mathbf{d x _ { \mathbf { i } }}$ are the meridional and zonal ${ }^{1}$ length of the grid box, with the vector direction pointing outwards from land. The negative sign implies net onshore transport has positive values, and vice versa.

To help portray the spatio-temporal distribution of TC moisture transport, the coastal grid boxes are numbered, ordered and segmented so that number 0-92 covers the western coast (green boxes in Figs. 6 and 7), 93-166 for the Gulf of Mexico (including Florida, in yellow), 167-252 for the eastern coast (in orange) and 253-275 for the Greater Antilles (in brown).

Figure 6 shows the Atlantic TC moisture flux distribution in 2005 using the scheme1-radii-900 scheme. The

\footnotetext{
${ }^{1}$ Note there exists a slight difference between the northern and the southern boundaries of a grid box, due to the shrinking latitudinal circles towards the pole.
}

western coast is mostly free from Atlantic TC influences (as seen in 2005 but also observed during 1980-2012, figure not shown), and is more directly impacted by TCs from the East Pacific (not shown, but included in Sect. 3.5). Note that as the attribution is based on geographical vicinity, possible impacts from East Pacific TCs on the detection of Atlantic TC's transport only occur when a grid box is affected by TCs from both basins at the same time. In such cases, attribution based on HURDAT2 (or IBTrACS) alone will possibly introduce some uncertainties along the western coast section where TCs from both sides may coincide, and the effect is likely a weakening of the fluxes by coinciding TCs from both sides. However, for scheme comparison and sensitivity test purposes this is not a significant issue, and the Atlantic TCs' transports are dominated by those along the eastern coast. Furthermore, when quantifying the interannual contributions by TCs in later 

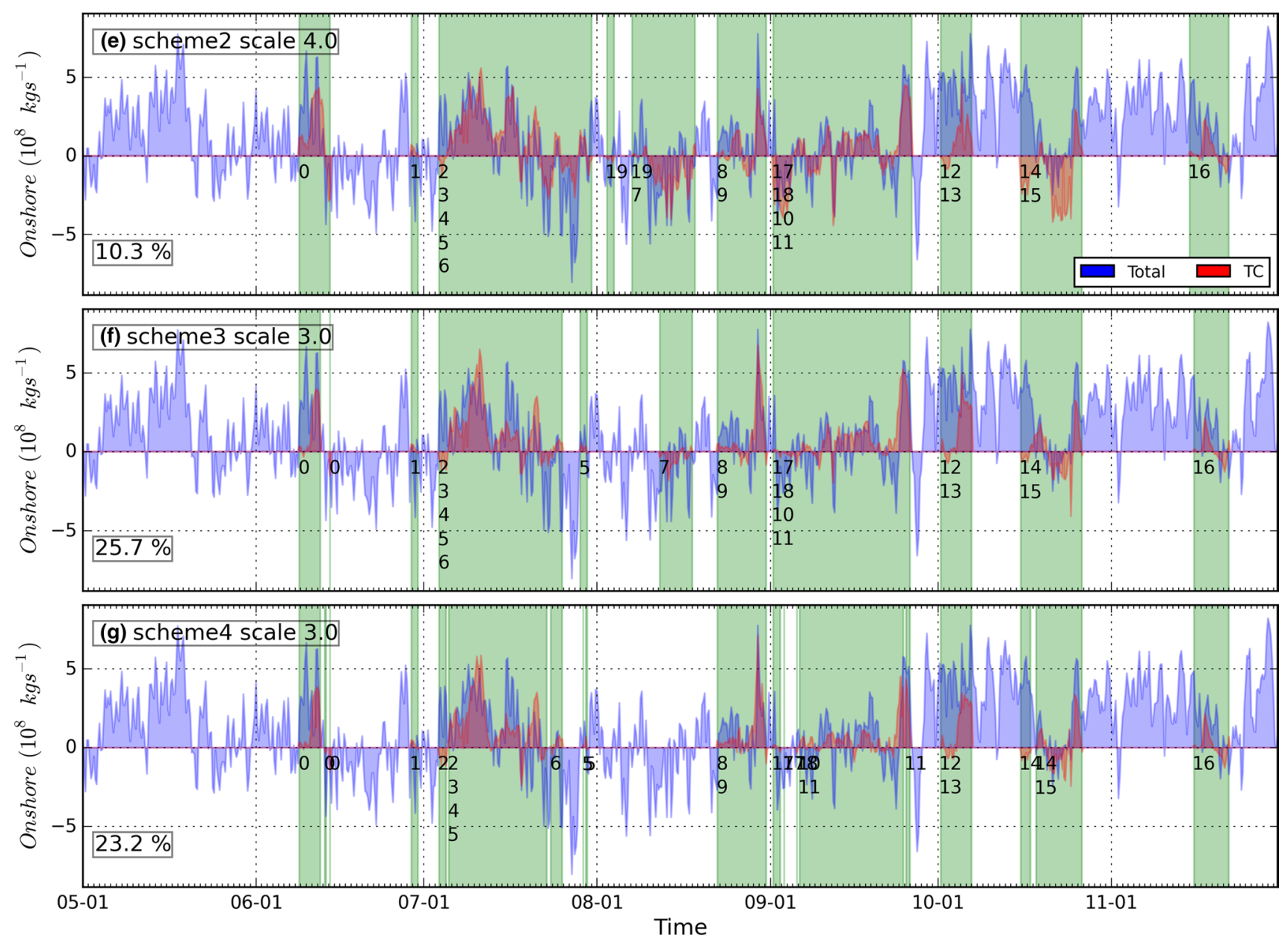

Fig. 9 Same as Fig. 8 but for $\mathbf{e}$ scheme-2-scale-4.0, $\mathbf{f}$ scheme-3-scale-3.0 and $\mathbf{g}$ scheme-4-scale-3.0

sections, we repeated the the analyses using a combined HURDAT2+IBTrACS best track, thus avoiding the doublecounting problem when summing up two seperate analyses, and properly addressing this uncertainty issue.

Much of the TC-induced moisture exchange occurred in the Gulf of Mexico section, within which 17 TCs made landfall in 2005. A few TCs steered along the eastern coast and induced some onshore transport along the coast of North Carolina, South Carolina and Pennsylvania during Sept and Oct (grid cells 167-190). Previous studies have suggested inter-annual variations in prefered TC tracks, and 2005 witnessed more landfalls and tracks in the Gulf of Mexico and west of the Appalachian Mts, compared to 2004 when more TCs visited the Atlantic coastal plains east of the Appalachian Mts (Brun and Barros 2014). Similar Gulf versus Atlantic differences are also reported in Konrad and Perry (2009), and are subject to influences from ENSO, Quasi-Biennial-Oscillation (QBO) and North Atlantic Oscillation (NAO) (Gray 1984; Pielke and Landsea 1999; Brun and Barros 2014; Dailey et al. 2009; Kim et al. 2009).
In addition to moistening, TCs also have a drying effect that takes moisture away from the continent, usually by the western or southern branch of the spiral bands. Within the Gulf of Mexico section, this particularly active year had two long-lasting moisture export/import zones that span 5-6 months, one on the Yucatan Peninsula of Mexico and the other covering Florida. The export zones are located to the south/west of their import counter-parts, with the TCs travelling between (indicated by the landfalling locations in Fig. 6). This is consistent with the cyclonic circulation and the broad orientation of the coastal lines. Due to the coarse resolution, small geographical area and island nature of the Greater Antilles, the flux response is very noisy.

The fixed $900 \mathrm{~km}$ scheme, although inflexible, constrains the TC's influence to a reasonable extent. When scaled by a large factor (e.g. 4.0), the scheme that picks the maximum wind radii of a TC can become very expansive for those large TCs. Figure 7 shows the distribution of Atlantic TC-fluxes during 2010 attributed using scheme2scale-4.0 scheme. Similar to the 2005 case, the Gulf of 
Table 2 Seasonal onshore moisture transport (Eg) by Atlantic TCs and total moisture flux during May-Nov 2005. The percentage contributed by TCs is obtained by dividing the net TC transport (column

\begin{tabular}{|c|c|c|c|c|c|c|c|}
\hline Scheme & TC positive (Eg) & TC negative & TC net & Total positive (Eg) & Total negative & Total net & TC percentage $(\%)$ \\
\hline Scheme-1-radii-700 & 0.55 & -0.12 & 0.43 & 3.20 & -1.06 & 2.14 & 19.9 \\
\hline Scheme-1-radii-900 & 0.75 & -0.13 & 0.61 & & & & 28.6 \\
\hline Scheme-2-scale- 2.0 & 0.54 & -0.15 & 0.39 & & & & 18.4 \\
\hline Scheme-2-scale-3.0 & 0.75 & -0.31 & 0.44 & & & & 20.7 \\
\hline Scheme-2-scale- 4.0 & 0.75 & -0.53 & 0.22 & & & & 10.3 \\
\hline Scheme-3-scale- 3.0 & 0.70 & -0.15 & 0.55 & & & & 25.7 \\
\hline Scheme-4-scale- 3.0 & 0.60 & -0.11 & 0.49 & & & & 23.2 \\
\hline Mean & 0.66 & -0.21 & 0.45 & 3.20 & -1.06 & 2.14 & 21.0 \\
\hline TC ID & TC Name & TC ID & TC Name & TC ID & TC Name & TC ID & TC Name \\
\hline 0 & Arlene & 6 & Gert & 12 & Stan & 18 & Nate \\
\hline 1 & Bret & 7 & Irene & 13 & Tammy & 19 & Harvey \\
\hline 2 & Cindy & 8 & Jose & 14 & Wilma & & \\
\hline 3 & Dennis & 9 & Katrina & 15 & Alpha & & \\
\hline 4 & Emily & 10 & Ophelia & 16 & Gamma & & \\
\hline 5 & Franklin & 11 & Rita & 17 & Maria & & \\
\hline
\end{tabular}

4) by the net total transport (column 7). Names of the TCs labelled in Fig. 8 and 9 are given in the lower section of the table, with each TC ID associated with a name
Mexico houses most of the TC-fluxes, however part of these may be falsely detected. Figure 7a highlights two TCs that have large sizes. After scaling by a factor of 4.0, Danielle's radius of influence goes up to $2667 \mathrm{~km}$, and Igor's to $3333 \mathrm{~km}$, both are clearly overestimated and extend into the Gulf of Mexico. Consequently, distant fluxes, either onshore or offshore, are falsely attributed to TCs. As will be seen later, the overall effect is likely to be an overestimate of the offshore fluxes.

\subsection{Coastally integrated TC onshore transport}

The overall TC contribution to continental scale onshore moisture transport is obtained by integrating along the coast lines:

$T=\sum_{i=1}^{N}\left(T_{u i}+T_{v i}\right)$

Applying the same computation to the absolute moisture flux (annual cycle plus anomaly) gives the total onshore transport onto the North American continent. The time series of Atlantic TC and total onshore transport during the 2005 TC season are shown in Figs. 8 and 9.

Consistent with previous discussions, a larger detection radius can pick up more distant TCs and create more long-lasting, continous TC transports, as indicated by the green shading in Fig. 8. More adaptable schemes tend to create intermittent hits-and-misses in the TC impact detection, as in the case of scheme-4-scale-3.0 (Fig. 9g). Despite 

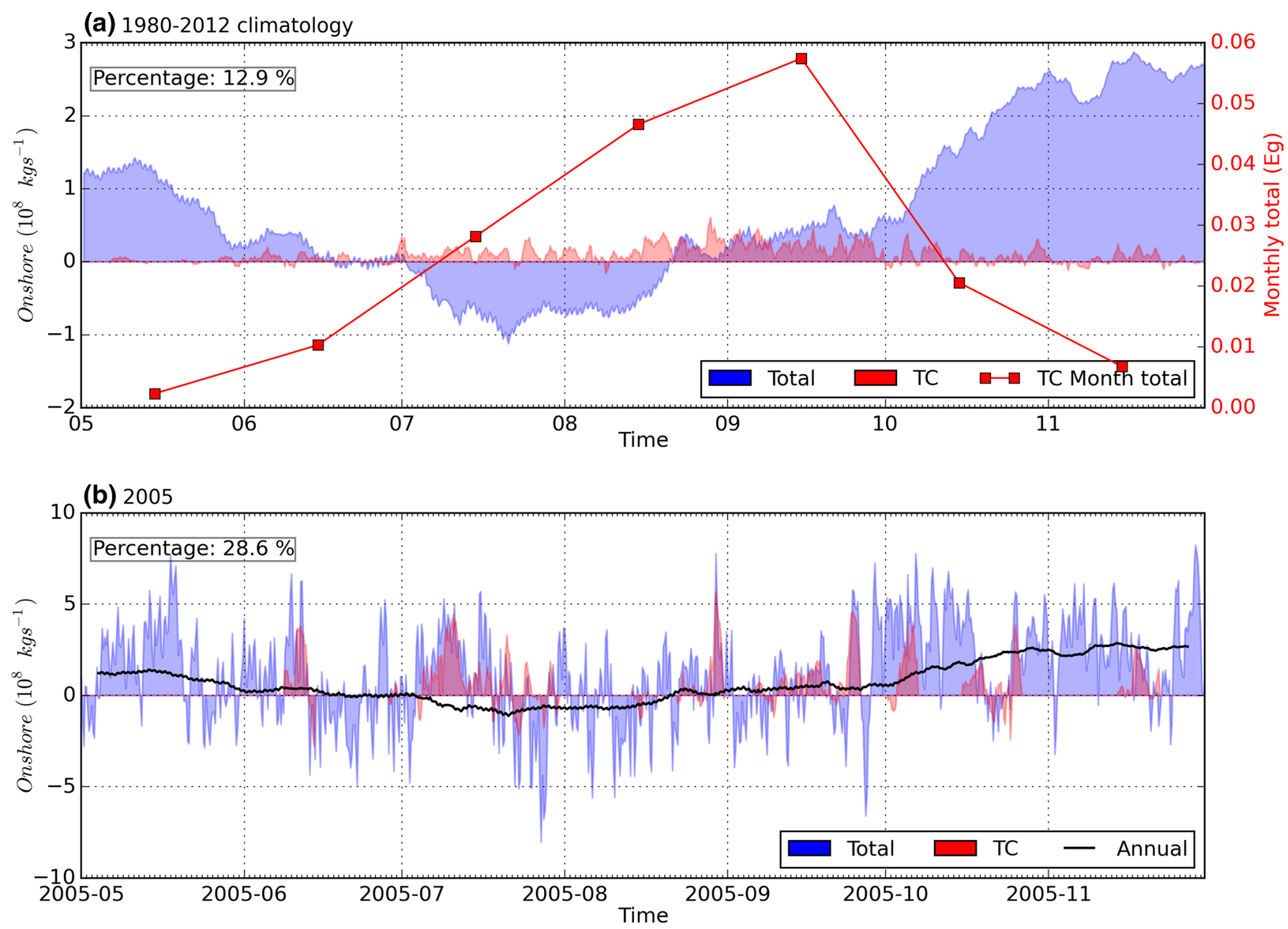

Fig. 10 Coastal integral of moisture transport $\left(\mathrm{kg} \mathrm{s}^{-1}\right)$ by Atlantic TCs (red) and the total moisture flux (blue), during May-Nov of the a 1980-2012 climatology and b year 2005. In both panels, the TC fluxes are computed using scheme-1-radii-900, and the total moisture flux includes annual cycle flux and flux anomalies. In a, the monthly

shown in Table 2, and the percentage contributions from TCs are included in Figs. 8, 9 and Table 2.

A total of $2.14 \mathrm{Eg}$ of water vapor was transported onto the North American continent from the western, southern and eastern coasts during May-Nov 2005, of which about $21 \%$ can be attributed to Atlantic TCs (mean of the seven schemes, Table 2). The percentage varies from $28.6 \%$ by scheme-1-radii-900, to $10.3 \%$ by scheme-2-scale-4.0. This most aggressive scheme scored the lowest percentage because both the onshore and offshore transports are highest and the offshore amount is especially large in absolute amount. This large drying flow is most prominent during mid-Aug, early-Sept and mid-Oct (Fig. 9).

Repeating the costal integration using scheme-1-radii-900 over period of 1980-2012 gives an estimation of the Atlantic TC moisture transport climatology, as shown in Fig. 10a. On average, September has the largest TC transport $(0.058 \mathrm{Eg})$, followed by August (0.047) and July integral of TC moisture transport $(\mathrm{Eg})$ is plotted onto the Y-axis on the right. The climatological annual cycle time series is smoothed by a 7-day filter, and the same time series is shown in $\mathbf{b}$ as the thick black line. The proportion of TC-transport to total seasonal transport is labelled at the top left corner in each panel

(0.028) when the climatological annual cycle flux indicates net offshore transport (blue shading in Fig. 10a). During the rest of the season, TC transport shows reduced intensity while the climatological annual cycle contributes much larger quantities. Integrated across the entire season, Atlantic TCs contribute around $13 \%$ of total net onshore moisture transport during May-Nov in 1980-2012.

When quantifying the proportional contribution by TCs as shown above, we have used the total moisture transport as the denominator. Taking out the annual cycle component, the ratio of TC- and anomaly- onshore transport gives a different view of the TC contribution. Moisture transported by Atlantic TCs detected by scheme-1-radii-900 constitutes $28.6 \%$ of the total net onshore transport in May-Nov 2005 (Figs. 8, Fig. 10b and Table 2), and the percentage goes to $74.8 \%$ if annual cycle fluxes are taken out. This high proportion is because (i) the anomalous flux is mostly dominated by TC-fluxes during TC affected time periods, and (ii) the 
(a)

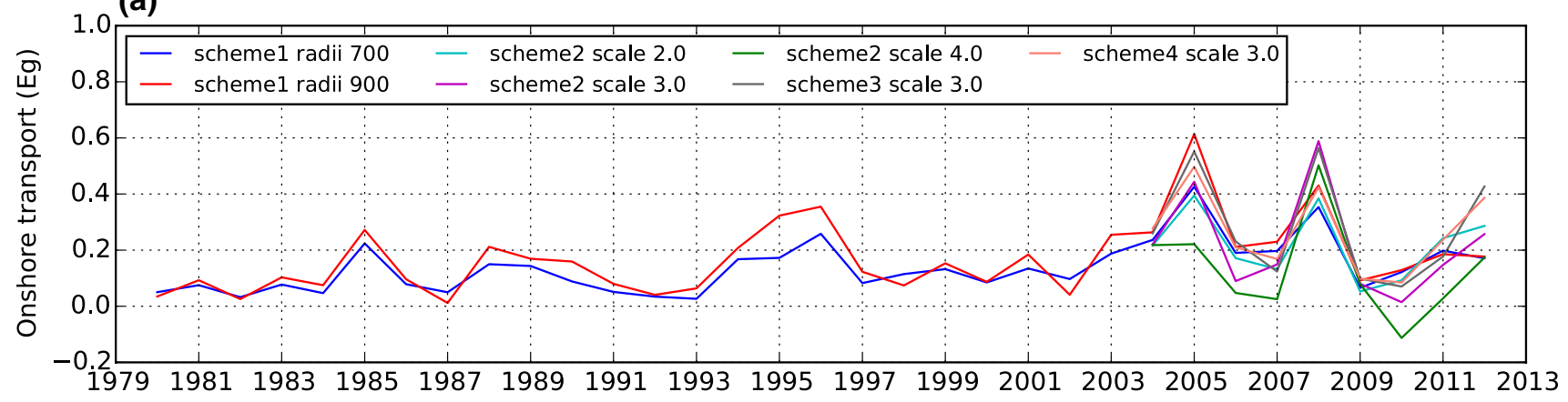

(b)

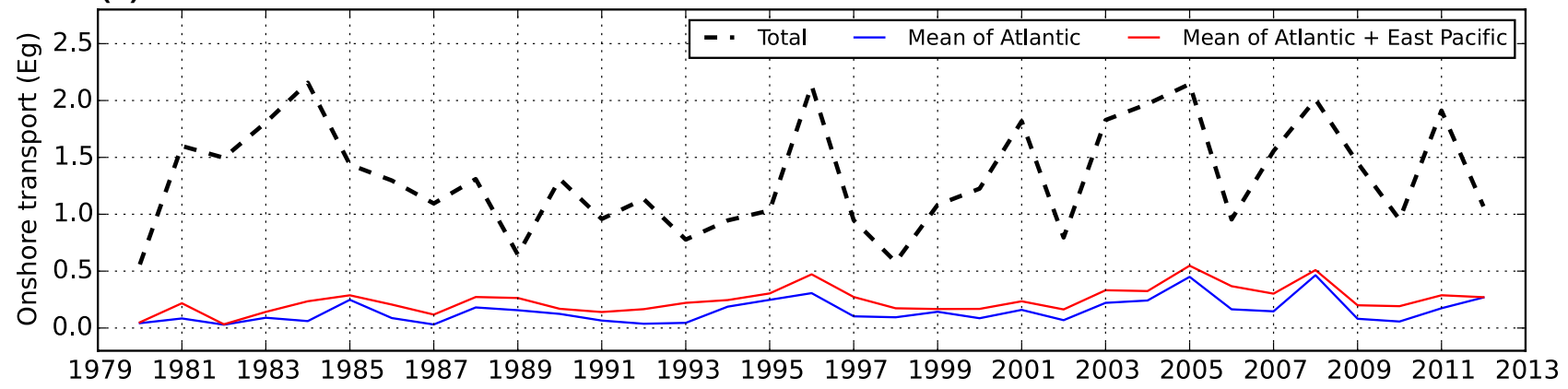

(c)

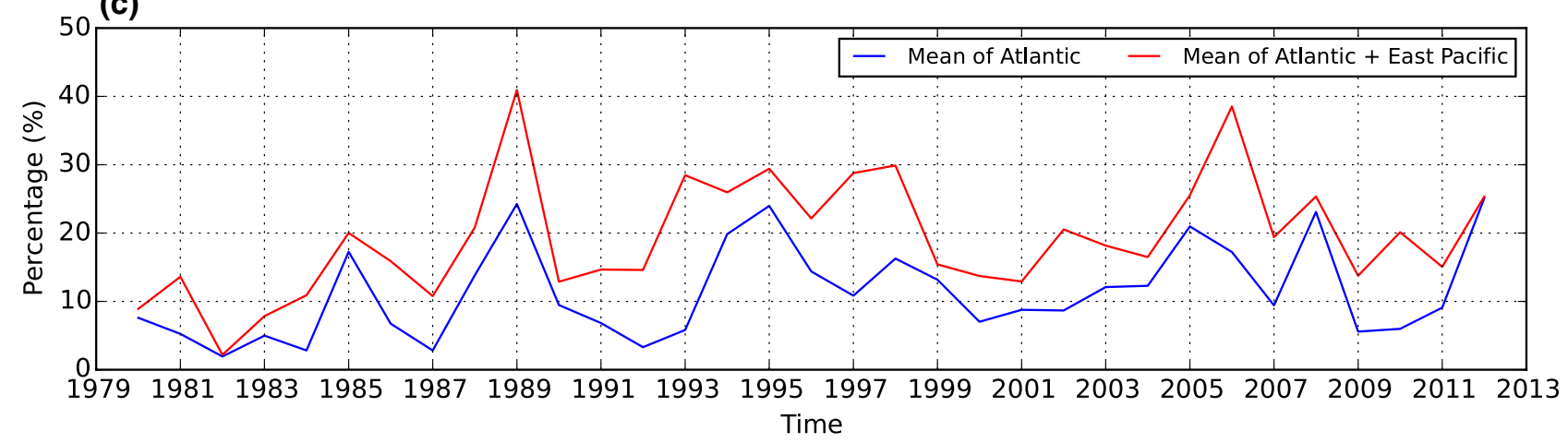

Fig. 11 a Comparison of the coastally-integrated seasonal (MayNov) net onshore moisture transports (Eg) by fluxes attributed to Atlantic TCs under different schemes. b Net onshore moisture transport $(\mathrm{Eg})$ by the total moisture flux (thick dashed black line), by fluxes attributed to Atlantic TCs (blue) according to the ensemble mean (mean of scheme1-radii-700 and scheme1-radii-900 dur-

TC-induced flux is more systematically orientated as onshore, while compensating offshore flows are sometimes present in the total anomaly transport. As landfalling TCs are usually associated with enhanced precipitation along the track, the air masses exiting the continent are more moisture-depleted.

\subsection{Inter-annual variability in TC onshore transport}

The previous section examines the Atlantic TC onshore transport in 2005 and the 1980-2012 climatology. To investigate the inter-annual variation, the same ing 1980-2003, mean of all ensemble members during 2004-2012), and by fluxes attributed to Atlantic and East Pacific TCs (red, mean of scheme1-radii-700 and scheme1-radii-900 during 1980-2012). c Percentage contribution to total seasonal onshore transport attributed to Atlantic (blue) or Atlantic and East Pacific (red) TCs using series from panel (b)

computation is repeated for 2004-2012 for all schemes, and extended back to 1980 for the scheme1-radii-700 and scheme1-radii-900 schemes. To give a more thorough view of the total TC contribution, we also included attributions to the East Pacific TCs using the scheme1-radii-700 and scheme1-radii-900 schemes, based on best track data from combined HURDAT2+IBTrACS. Figure 11 shows timeseries of seasonal onshore transport in total and the component attributed to Atlantic and Atlantic+East Pacific TCs, and the corresponding TC percentage of the total net transport. 
Table 3 Percentage (\%)

contribution to hurricane-season ocean-to-land moisture transport attributed to TCs according to period and attribution scheme

\begin{tabular}{lllll}
\hline & Atlantic & Atlantic & Atlantic & Atlantic + East Pacific \\
\hline Scheme & $2004-2012$ & $1980-2003$ & $1980-2012$ & $1980-2012$ \\
Scheme1-700 & 14.0 & 9.4 & 10.6 & 16.9 \\
Scheme1-900 & 16.3 & 11.3 & 12.7 & 21.8 \\
Scheme1 mean & 15.2 & 10.3 & 11.7 & 19.4 \\
Scheme2-2.0 & 14.2 & N/A & N/A & N/A \\
Scheme2-3.0 & 13.2 & N/A & N/A & N/A \\
Scheme2-4.0 & 7.1 & N/A & N/A & N/A \\
Scheme3-3.0 & 18.1 & N/A & N/A & N/A \\
Scheme4-3.0 & 17.3 & N/A & N/A & N/A \\
Mean over all schemes & 14.3 & 10.3 & $11.4 *$ & 19.4 \\
\hline
\end{tabular}

* the 1980-2012 climatology is the weighted average of the two sub-periods including all schemes available: $(10.3 \times 24+14.3 \times 9) / 33=11.4$

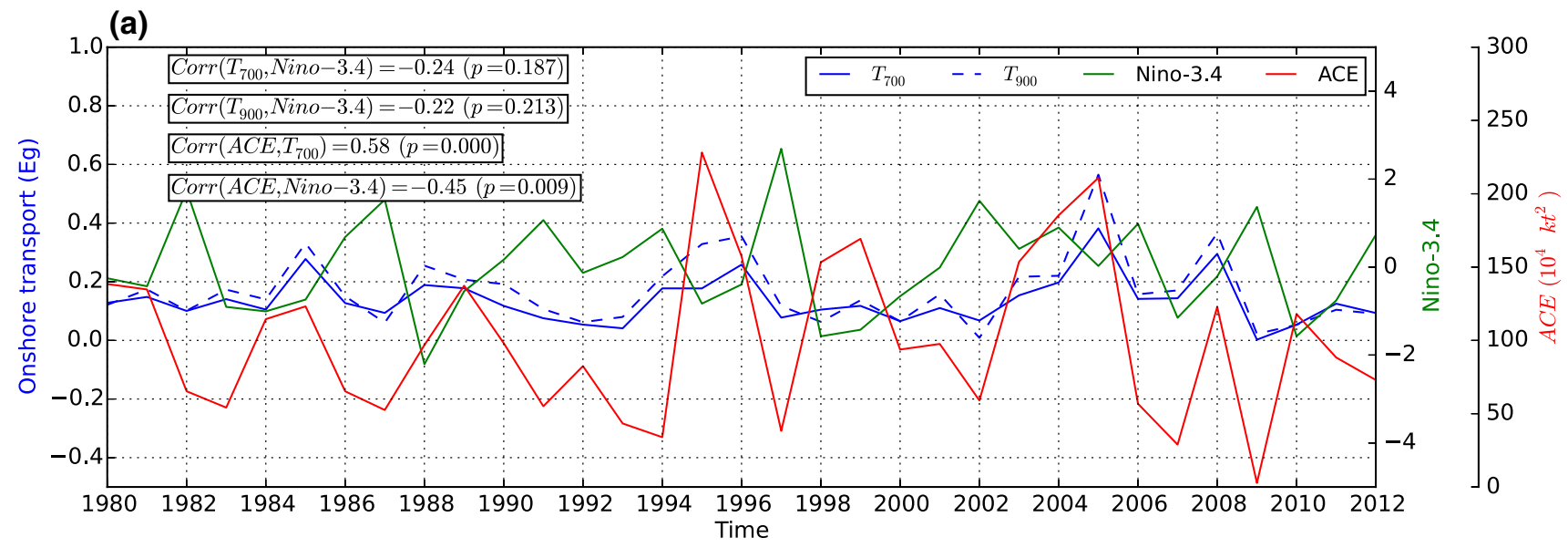

(b)

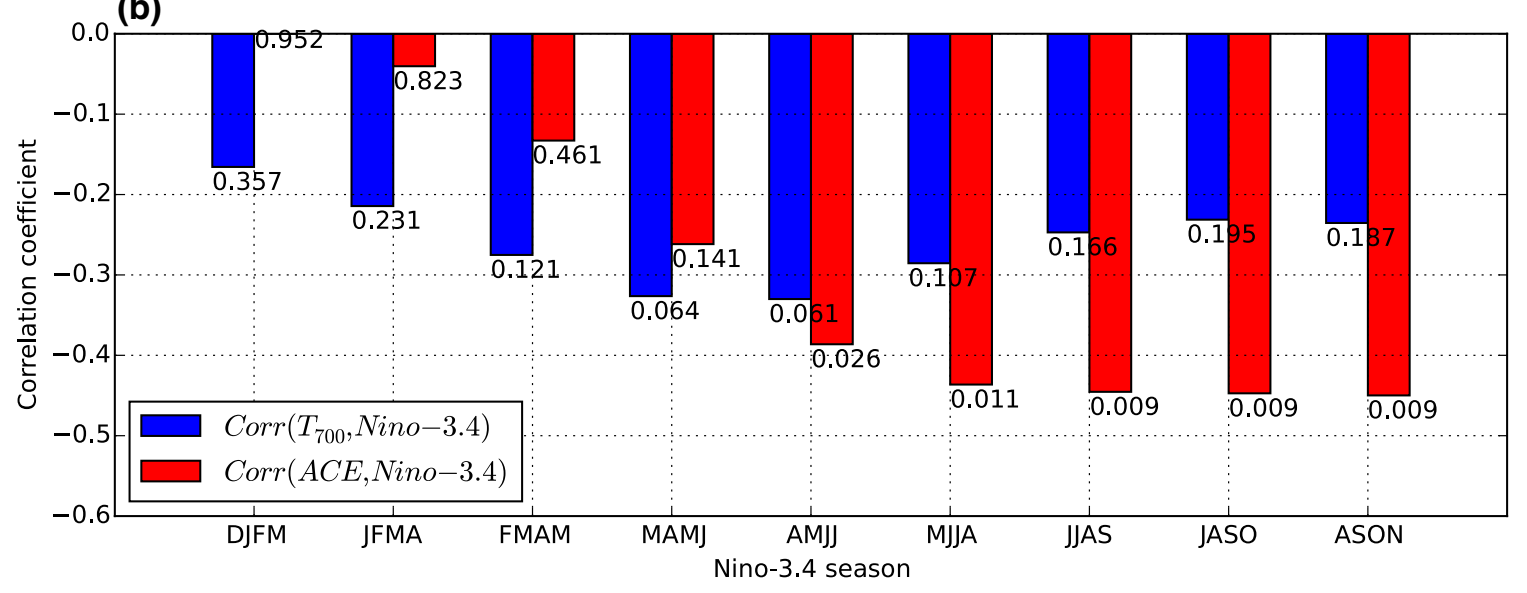

Fig. 12 a Time series of seasonal Atlantic TC onshore transport $(E g)$ during 1980-2012, detected using scheme1-radii-700 ( $T_{700}$, blue solid line) and scheme1-radii-900 scheme ( $T_{900}$, blue dashed line $)$. The seasonal ACE indices $\left(10^{4} k t^{2}\right)$ are plotted in red onto the rightmost Y-axis. Seasonal average (Aug-Nov, ASON) Nino-3.4 indices are plotted in green onto the second Y-axis from right. Linear trends in all time series have been removed. Some correlation results are shown at the top-left corner. b The blue (red) bars show correlation coefficients between the May-Nov seasonal $T_{700}$ (ACE) and Nino-3.4 indices computed using different season definitions, ranging from the DJFM season prior to the TC season, to ASON during the later part of the same TC season. $p$ values of the correlations are labelled correspondingly 
Estimates from the full ensemble of schemes are available during 2004-2012 for Atlantic TCs, within which good agreement is observed in 2004 and 2009. For the other seven years, there is a wide spread among them, typically $0.25 \mathrm{Eg}$ but in 2005 the spread reaches $0.39 \mathrm{Eg}$ (Fig. 11a, Table 2). No scheme is always higher or lower than the others, but scheme2-scale-4.0 gives the lowest estimate for all years except 2008 and 2009. In 2010 this latter scheme reports a negative net TC transport $(-0.11 E g)$, caused by falsely attributed offshore fluxes discussed previously. Despite differences in the TC-attributed net transports, the schemes do agree on the years with greater or less TC transports. This is reflected in the significant correlations observed among all schemes during 2004-2012, with the lowest correlation being 0.64 ( $p=0.06$ ) bewteen scheme1radii-900 and scheme2-scale-4.0, and highest correlation being $0.97(p<0.01)$ between scheme2-scale-2.0 and scheme4-scale-3.0. This suggests a consistent and robust inter-annual variability in TC transport that is relatively insensitive to the detection scheme.

During the period of 2004-2012, 2005 and 2008 stand out with large Atlantic and East Pacific TC transport in both the absolute and percentage senses. Despite the total transport in these two years being among the highest in the record, the percentage contributions from Atlantic TCs still reach $21.0 \%$ (ensemble mean, ensemble range is $10.3-28.8 \%$ ) and $23.1 \%$ (ensemble mean, range: $17.6-$ $29.3 \%$ ), respectively. With contributions from East Pacific TCs included, the percentages rise to $25.5 \%$ and $25.4 \%$ (mean of scheme1-radii-700 and scheme1-radii-900), respectively. Transports by Atlantic TCs in 2007, 2009 and 2010 are lower than these two years by about $70 \%$ to $87 \%$ (based on ensemble means), and the 2010 mean is the lowest $(0.06 \mathrm{Eg})$ during 2004-2012. 2006, 2011 and 2012 have moderate TC transport, with ensemble means of $0.16 E g, 0.17 E g$ and $0.27 \mathrm{Eg}$, respectively. These are mostly consistent with the variation in TC-attributed precipitation by Brun and Barros (2014). However, they identified 2004 as the most TC-impacted year during 2002-2011, exceeding 2005 despite more major hurricanes in the latter. The difference was suggested to be related with the Atlantic versus Gulf of Mexico alignments of the storm tracks, because orographic effects can vary greatly correspondingly (Konrad and Perry 2009; Brun and Barros 2014). Here, moisture onshore transport is about $50 \%$ lower in 2004 than in 2005 (Fig. 11). This discrepency illustrates that although a positive relationship is expected, the underlying processes of TC onshore moisture transport and precipitation are distinct (Schumacher and Galarneau 2012). Responses of precipitation to TCs may vary substantially, controlled not only by the moisture plume advected by the TCs but also by interactions with extra-tropical features, including upper level divergence and the presence of a front at the time of TC arrival (Konrad and Perry 2009).

The use of fixed radius schemes allows the estimation to be made back to 1980. Scheme1-radii-700 and scheme1radii-900 report largely consistent TC onshore transport during 1980-2004 (Fig. 11a), with a correlation coefficient of $0.96(p<0.01)$. The variability is also closely related to TC activity measurements, for instance a significant correlation $(R=0.70, p<0.01)$ is found between the scheme1radii-700 estimates and the TC number timeseries as shown in Fig. 1d, as well as with the Accumulated Cyclone Energy (ACE) index (shown in the next section and in Fig. 12). A weak increasing trend can be observed in both of the Scheme1-radii-700 and Scheme1-radii-900 timeseries, although neither is statistically significant (by a Mann-Kendall trend test).

On average, $0.15 \mathrm{Eg}$ (ensemble mean) of moisture, equivalent to $11.4 \%$ (Table 3 ) of seasonal onshore moisture transport can be attributed to Atlantic TCs during 1980 2012, which is of comparable magnitude as the precipitation percentages $(10 \%$ of Florida's annual rainfall (Knight and Davis 2007); 4-15\% of the South East US (Rodgers et al. 2001; Knight and Davis 2009; Konrad and Perry 2009; Prat and Nelson 2013)). The mean value for 19801994, a relatively quiet TC period (Goldenberg 2001), is $8.8 \%$, and the mean for the more active 1994-2012 period is $14.1 \%$. However, the percentage variation is affected by both the TC-attributed and the total transport. The relatively high percentage values during the 1985-1995 decade are partly caused by lower total transport (Fig. 11). Similarly, the 2012 percentage in some of the schemes exceeds that in 2005, as the total transport is much lower in 2012.

Contributions by East Pacific TCs are also considered using the two fixed radii schemes. In general, less moisture is transported by East Pacific TCs than by the Atlantic ones (Fig. 11b, c). However, in some cases the amounts are comparable, or even higher, such as in 1993 and 1997. Timeseries of the East Pacific TC transport have mixed positive and negative correlations with their Atlantic counter-parts during different periods (not shown), and overall no significant correlation is observed. With this component added, moisture transport by TCs from both basins constitutes around $0.24 \mathrm{Eg}$ (19.4\% of total) during 1980-2012.

\section{Conclusions and disscussion}

\subsection{TC onshore flux and its inter-annual variability}

TC-related moisture transports across the North America coasts are quantified in this study. Distribution of these transports corresponds well with TC tracks. The Gulf of 
Mexico and the eastern Atlantic coast house the majority of influcencing TCs, and onshore (offshore) transport is typically observed on the right (left) side of the TC center. As the land usually experiences heavy precipiation in response to a TC's landfall, the air masses leaving the continent from the south-west side are more moisture depleted. Combined with slightly weaker winds on the western quadrants, the TC-related net moisture transport is more systematically orientated as onshore. After integration along the coast line, impacts from TCs can dominate the total onshore transport during affected periods.

Contribution from Atlantic TCs to seasonal onshore transport across the western, southern and eastern coasts of North America is around $11.4 \%$ for the 1980-2012 period, with the highest percentage reaching $25.1 \%$ (ensemble mean in 2012). During 2004-2012, ensemble members show largely consistent inter-annual varability, which is also broadly consistent with TC-related precipitation changes (Brun and Barros 2014). Among the ensemble members, no scheme constantly produces higher or lower estimates than the others, but one attribution scheme (scheme2-scale-4.0) produces lower estimates in all but two years and this contributes strongly to an average ensemble spread of $0.25 \mathrm{Eg}$ during 2004-2012. The latter scheme is perhaps the most "aggressive" one, taking the quadruple of $34 \mathrm{kt}$ wind radii of a TC as the attribution threshold. This was shown to be an overestimate for large-sized TCs, and the overall effect is influenced by capturing more offshore flows, giving a lower net TC transport.

\subsection{Uncertainties in the TC flux attribution}

The size of a TC's impact area is a critical parameter in the attribution process, and giving an objective definition of the TC size is a difficult task (Liu and Chan 1999). Several different definitions have been used in previous studies, including the radius of the outer closed isobar (ROCI) (Liu and Chan 1999; Merrill 1984; Konrad et al. 2002; Konrad and Perry 2009), the radial extent of 15, 17 and $25 \mathrm{~m} / \mathrm{s}$ winds (R-15, R-17 and R-25) (Weatherford and Gray 1988), and radial extent of a threshold relative vorticity (Liu and Chan 1999). A fixed $500 \mathrm{~km}$ radius is a common choice in precipitation-TC studies (Rodgers et al. 2001; Larson et al. 2005; Lau et al. 2008; Jiang and Zipser 2010), or as a buffer zone for the landfalling TCs (Nogueira and Keim 2011). Case studies on two sample locations suggest that the commonly used $500 \mathrm{~km}$ radius is too conservative to capture the full extent of moisture flux responses. In fact, the same concern has been raised in relation to precipitation attributions (Dare et al. 2012; Rodgers et al. 2001). As the detection radius increases, so does the risk of false positive errors. In such cases, the removal of an estimated background flow can help reduce the error. However, the accuracy of the background estimation drops as the duration of TC-impact increases, which is a natural response to an inflated detecting radius. Incorporating extra flexibility into the detecting radius, by addressing shape asymmetry of TCs or their time varying sizes, has limited added value in improving the detection accuracy. The current method is a compromise and further improvements are possible. For instance, all distancebased attribution methods resort to a binary type detection strategy: a grid box at any time is either affected or not by a nearby TC, and can jump between the two states, either due to changes in the distance or if a different scheme is used. A smooth kernel with decreasing weights, e.g. multivariate Gaussian, may help reduce the sensitivity to threshold radius definition, and the risks of false positive errors as well.

The temporal extent has been restricted to the life time of TCs. This decision can lead to a scenario that significant anomalous flows are ignored because a TC has not yet fully developed (and not yet recorded into best track data) or has already dissipated. The ambiguity of whether the preceding and aftermath flows are associated with a TC should always be made clear moving from one context to another. Previous studies have identified precedent precipitation events (PREs) that are closely related to moisture transport prior to the arrival of some landfalling TCs (Galarneau et al. 2010; Schumacher and Galarneau 2012). In some cases, these PREs lead the TC arrival time by 36 hours, or 1000 $\mathrm{km}$ poleward of the TC (Galarneau et al. 2010). However, not every landfalling TC is associated with such PRE events. A robust detection scheme should have the flexibility to adjust to different situations.

To evaluate the uncertainties associated with misalignment of TC centers in ERA-I and best track, we detected RV maxima from the vicinity of two selected TCs as the TC centers of ERA-I. Although the results suggest overall good agreement with best track, the misalignment may be larger in the early part of ERA-I. Using a similar detection method, Jourdain et al. (2014) reported increasing TC postional errors in ERA-I back to the 1980s, when compared with the records from IBTrACS. The largest offsets are around $180 \mathrm{~km}$ for the less intense TCs (see their Fig. 3). Assuming random directional distribution in the offsets, the uncertainty range due to ERA-I positional error could be similar to the differences between fixed $700 \mathrm{~km}$ and $900 \mathrm{~km}$ schemes. Considering the overall good agreement between the two (Fig. 11), this positional error is not contributing much to the estimation uncertainty.

Another source of error comes from the TC wind field in reanalysis. The maximum wind speed in the vicinity of TCs was found to be underestimated in magnitude (Bengtsson et al. 2007; Jourdain et al. 2014) but overestimated in its lateral extent (Jourdain et al. 2014). For ERA-I, the 
bias of maximum wind speed is about $-9 \mathrm{~m} / \mathrm{s}$ for storms and $-27 \mathrm{~m} / \mathrm{s}$ for hurricanes, while the sizes of the TCs are overestimated by about $210 \mathrm{~km}$ (Jourdain et al. 2014). Both suggest a significant deficit in realistically depicting TCs by reanalysis products. The resultant uncertainty in the integrated moisture flux is difficult to estimate, as it is column integrated over the entire atmosphere not only the surface. Although it is heavily weighted towards the boundary layer, the moisture transport associated with TCs can extend up to the tropopause (Schumacher and Galarneau 2012). Assuming the low biased wind speed and high biased radial extent are systematic within the troposphere, the combined effect is likely to be an underestimated transport.

\subsection{Relationship with TC precipitation}

Like precipitation, the TC-related onshore moisture transport is also a freshwater influx to the land so these two quantities should be positively related but not identicial. Firstly, enhanced precipitation due to a TC does not originate only from additional ocean-to-land water vapor transport: contributions may also be made from water vapor already present in the atmosphere, from convergence over land (Schumacher and Galarneau 2012), and to a lesser extent from evapotranspiration during the passage of the TC. Secondly, additional moisture transport by the TC is favourable to enhanced precipitation but does not guarantee it. Hurricane Hugo in 1989 made landfall in South Carolina causing around one billion dollars of damage by its strong winds, but only produced modest rainfall (Konrad and Perry 2009; Cline 2002). On the other hand, not every heavy rainfall coinciding with TCs can be attributed to TCs (Konrad and Perry 2009; Schumacher and Galarneau 2012). The timing, location, and magnitude of ascent associated with synoptic-scale features are just as important in determining when and where heavy rain will occur (Konrad and Perry 2009; Schumacher and Galarneau 2012). Lastly, the atmospheric moisture exchange across the coastline is relevant to the continental-scale water budget, but precipitation responses are relevant in both coastal and inland areas. Landfalling TCs and their associated rainfall generally weaken quickly due to the isolation of the inner core from the warm, moist ocean surface (Ren et al. 2007; Knight and Davis 2009; Dare et al. 2012). Despite this general weakening, interactions with other synoptic systems (Konrad and Perry 2009; Dare et al. 2012) or local orography (Brun and Barros 2014) may continue to produce rainfall further inland.

\subsection{Relationship with ENSO and future work}

It is of great importance to investigate the relations of TC moisture transport with well known modes of climate variability, including ENSO, NAO and QBO. As this is planned in a future work we will only give some shorter comments on the ENSO relationship here.

Previous studies have documented an ENSO influcence on Atlantic TC activity (e.g. Gray 1984; Pielke and Landsea 1999; Goldenberg 2001; Smith et al. 2007; Bengtsson et al. 2007). Enhanced subsidence and vertical wind shear develop over the tropical Atlantic, in response to anomalous central/eastern Pacific warming during El Niños. Consequently, surpressed Atlantic TC activity is observed during warm years, and the opposite for cold years (Gray 1984). This negative relationship bewteen TC activity (represented by ACE) and central Pacific SST (represented by Nino-3.4 index) can be observed in Fig. 12. Correspondingly one might expect a similar negative relationship between Nino-3.4 and the seasonal TC moisture transport. However, this relationship is much weaker and not statistically significant. Besides, there seems to be a time shift bewteen these two relationships: ACE is most sensitive to the Aug-Nov (ASON) season Nino-3.4 SST (Fig. 12a, b), while the peak correlation with TC transport is observed with the April-July (AMJJ) Nino-3.4 index. This lack of correspondence is partially because, in addition to anomalous TC activity, effective onshore transport also requires properly aligned tracks, therefore landfalling locations in different ENSO phases need to be incorporated. Smith et al. (2007) noticed that despite generally enhanced TCs during La Niña years, there is little difference in the probability of hurricane landfalls in Florida or along the Gulf coast compared with neutral years, and these areas are most conducive to onshore transport as shown in our results. Lastly, the conventional El Niño versus La Niña way of looking at ENSO variability needs to be updated. Many studies have reported a systematic difference between an Eastern Pacific (EP) El Niño and a Central Pacific (CP) El Niño with distinct features in many aspects (Kao and Yu 2009; Kug et al. 2009; $\mathrm{Xu}$ et al. 2015), including Atlantic TC activities (Kim et al. 2009; Wang et al. 2014). In particular, the CP El Niños were found to enhance Atlantic TCs in contrast to surppression by EP El Niños (Kim et al. 2009). Taking into account the observed increasing frequency of CP El Niños after 1990s (Kim et al. 2009), greater complexity is added to the responses to ENSO variability.

\subsection{Concluding remarks}

TCs from different ocean basins have systematic differences in their sizes (Jiang and Zipser 2010), and in particular the Atlantic TCs are typically smaller compared with those in northwest Pacific, South Pacific and Indian Ocean regions. Therefore care should be taken in applying the methods to other basins. The suggested $11 \%$ average TC contribution gives an indication of the uncertainty in the 
simulated ocean-to-land moisture transport due to inadequately resolved TCs by climate models. Finally, horizontal resolution of the model is an important factor for both the ocean-to-land moisture fluxes (Demory et al. 2013) and a realistic simulation of TCs (Strachan et al. 2013).

Acknowledgments We thank Manoj Joshi for valuable suggestions during the process of this work. The ERA-Interim data were extracted from ECMWF website: http://apps.ecmwf.int/datasets/data/ interim_full_daily/. HURDAT2 data were obtained from the Hurricane Research Division of NOAA: http://www.aoml.noaa.gov/hrd/ hurdat/Data_Storm.html. And IBTRACS data were obtained from the National Climate Data Center (NCDC) from NOAA: https://www. ncdc.noaa.gov/ibtracs/. The research presented in this paper was carried out on the High Performance Computing Cluster supported by the Research and Specialist Computing Support service at the University of East Anglia.

Open Access This article is distributed under the terms of the Creative Commons Attribution 4.0 International License (http://creativecommons.org/licenses/by/4.0/), which permits unrestricted use, distribution, and reproduction in any medium, provided you give appropriate credit to the original author(s) and the source, provide a link to the Creative Commons license, and indicate if changes were made.

\section{References}

Bengtsson L, Hodges KI, Esch M (2007) Tropical cyclones in a T159 resolution global climate model: comparison with observations and re-analyses. Tellus A 59(4):396-416. doi:10.1111/j.1600-0870.2007.00236.x

Brun J, Barros AP (2014) Mapping the role of tropical cyclones on the hydroclimate of the southeast United States: 2002-2011. Int J Climatol 34(2):494-517. doi:10.1002/joc.3703

Cline J (2002) Surface-based rain, wind, and pressure fields in tropical cyclones over North Carolina since 1989. Tech. rep, National Weather Service Offic, Bohemia, New York

Dailey PS, Zuba G, Ljung G, Dima IM, Guin J (2009) On the relationship between North Atlantic sea surface temperatures and U.S. hurricane landfall risk. J Appl Meteorol Climatol 48(1):111-129. doi:10.1175/2008JAMC1871.1

Dare RA, Davidson NE, McBride JL (2012) Tropical cyclone contribution to rainfall over Australia. Mon Weather Rev 140(11):3606-3619. doi:10.1175/MWR-D-11-00340.1

Dee DP, Uppala SM, Simmons AJ, Berrisford P, Poli P, Kobayashi S, Andrae U, Balmaseda MA, Balsamo G, Bauer P, Bechtold P, Beljaars ACM, van de Berg L, Bidlot J, Bormann N, Delsol C, Dragani R, Fuentes M, Geer AJ, Haimberger L, Healy SB, Hersbach H, Hólm EV, Isaksen L, Kållberg P, Köhler M, Matricardi M, McNally AP, Monge-Sanz BM, Morcrette JJ, Park BK, Peubey C, de Rosnay P, Tavolato C, Thépaut JN, Vitart F (2011) The ERA-Interim reanalysis: configuration and performance of the data assimilation system. Q J R Meteorol Soc 137(656):553597. doi:10.1002/qj.828

Demory ME, Vidale PL, Roberts MJ, Berrisford P, Strachan J, Schiemann R, Mizielinski MS (2013) The role of horizontal resolution in simulating drivers of the global hydrological cycle. Clim Dyn 42(7-8):2201-2225. doi:10.1007/s00382-013-1924-4

Emanuel K (2005) Increasing destructiveness of tropical cyclones over the past 30 years. Nature 436(7051):686-688. doi:10.1038/ nature 03906
Galarneau TJ, Bosart LF, Schumacher RS (2010) Predecessor rain events ahead of tropical cyclones. Mon Weather Rev 138(8):3272-3297. doi:10.1175/2010MWR3243.1

Goldenberg SB (2001) The recent increase in Atlantic Hurricane activity: causes and implications. Science 293(5529):474-479. doi:10.1126/science. 1060040

Gray WM (1984) Atlantic seasonal hurricane frequency. Part I: El Niño and $30 \mathrm{mb}$ quasi-biennial oscillation influences

Hart RE, Maue RN, Watson MC (2007) Estimating local memory of tropical cyclones through MPI anomaly evolution. Mon Weather Rev 135(12):3990-4005. doi:10.1175/2007mwr2038.1

Jiang H, Zipser EJ (2010) Contribution of tropical cyclones to the global precipitation from eight seasons of TRMM data: regional, seasonal, and interannual variations. J Clim 23(2005):15261543. doi:10.1175/2009JCLI3303.1

Jourdain NC, Barnier B, Ferry N, Vialard J, Menkes CE, Lengaigne M, Parent L (2014) Tropical cyclones in two atmospheric (re) analyses and their response in two oceanic reanalyses. Ocean Model 73(2014):108-122. doi:10.1016/j.ocemod.2013.10.007

Kao HY, Yu JY (2009) Contrasting Eastern-Pacific and CentralPacific types of ENSO. J Clim 22(3):615-632. doi:10.1175/200 8JCLI2309.1

Kim HM, Webster Peter J, Curry JA (2009) Impact of shifting patterns of Pacific Ocean warming on North Atlantic tropical cyclones. Science 325(5936):77-80. doi:10.1126/science.1174062

Knaff JA, Zehr RM (2007) Reexamination of tropical cyclone wind pressure relationships. Weather Forecast 22(1):71-88. doi:10.1175/WAF965.1

Knaff JA, Sampson CR, DeMaria M, Marchok TP, Gross JM, McAdie CJ (2007) Statistical tropical cyclone wind radii prediction using climatology and persistence. Weather Forecast 22(4):781-791. doi:10.1175/WAF1026.1

Knapp KR, Kruk MC, Levinson DH, Diamond HJ, Neumann CJ (2010) The international best track archive for climate stewardship (IBTrACS). Bull Am Meteorol Soc 91(3):363-376. doi:10.1 175/2009BAMS2755.1

Knight DB, Davis RE (2007) Climatology of tropical cyclone rainfall in the southeastern United States. Phys Geogr 28(2):126-147. doi:10.2747/0272-3646.28.2.126

Knight DB, Davis RE (2009) Contribution of tropical cyclones to extreme rainfall events in the southeastern United States. J Geophys Res 114(D23):D23,102. doi:10.1029/2009JD012511

Konrad CE, Perry LB (2009) Relationships between tropical cyclones and heavy rainfall in the Carolina region of the USA. Int J Climatol 534:522-534. doi:10.1002/joc.1894

Konrad CE, Meaux MF, Da Meaux (2002) Relationships between tropical cyclone attributes and precipitation totals: considerations of scale. Int J Climatol 22(2):237-247. doi:10.1002/joc.721

Kug JS, Jin FF, An SI (2009) Two types of El Niño events: cold tongue El Niño and warm pool El Niño. J Clim 22(6):1499_ 1515. doi:10.1175/2008JCLI2624.1

Landsea CW, Franklin JL (2013) Atlantic hurricane database uncertainty and presentation of a new database format. Mon Weather Rev 141:3576-3592. doi:10.1175/MWR-D-12-00254.1

Larson J, Zhou Y, Higgins RW (2005) Characteristics of landfalling tropical cyclones in the United States and Mexico: Climatology and interannual variability. J Clim 18(8):1247-1262. doi:10.1175/JCLI3317.1

Lau KM, Zhou YP, Wu HT (2008) Have tropical cyclones been feeding more extreme rainfall? J Geophys Res Atmos 113(23):1-12. doi:10.1029/2008JD009963

Liu KS, Chan JCL (1999) Size of tropical cyclones as inferred from ERS-1 and ERS-2 Data. Mon Weather Rev 127(12):2992-3001

Lowe DG (2004) Distinctive image features from scale-invariant keypoints. Int J Comput Vision 60(2):91-110. doi:10.1023/B:V ISI.0000029664.99615.94 
Maxwell JT, Soulé PT, Ortegren JT, Pa Knapp (2012) Drought-busting tropical cyclones in the southeastern Atlantic United States: 1950-2008. Ann Assoc Am Geogr 102(2):259-275. doi:10.1080/ 00045608.2011.596377

Merrill RT (1984) A comparison of large and small tropical cyclones. Mon Weather Rev 112(7):1408-1418

Nogueira RC, Keim BD (2011) Contributions of Atlantic tropical cyclones to monthly and seasonal rainfall in the eastern United States 1960-2007. Theoret Appl Climatol 103(1-2):213-227. doi:10.1007/s00704-010-0292-9

Pielke Ra, Landsea CN (1999) La Nina, El Nino, and Atlantic Hurricane damages in the United States. Bull Am Meteorol Soc 80(10):2027-2033

Prat OP, Nelson BR (2013) Precipitation contribution of tropical cyclones in the southeastern United States from 1998 to 2009 using TRMM satellite data. J Clim 26(3):1047-1062. doi:10.1175/JCLI-D-11-00736.1

Price JF, Sanford TB, Forristall GZ (1994) Forced stage response to a moving Hurricane. J Phys Oceanogr 24(2):233-260

Ren F, Wu G, Dong W, Wang X, Wang Y, Ai W, Li W (2006) Changes in tropical cyclone precipitation over China. Geophys Res Lett 33(20):L20,702. doi:10.1029/2006GL027951

Ren F, Wang Y, Wang X, Li W (2007) Estimating tropical cyclone precipitation from station observations. Adv Atmos Sci 24(4):700711. doi:10.1007/s00376-007-0700-y

Rodgers EB, Adler RF, Pierce HF (2001) Contribution of tropical cyclones to the North Atlantic climatological rainfall as observed from satellites. J Appl Meteorol 40(11):1785-1800
Schumacher RS, Galarneau TJ (2012) Moisture transport into midlatitudes ahead of recurving tropical cyclones and its relevance in two predecessor rain events. Mon Weather Rev 140(6):1810 1827. doi:10.1175/MWR-D-11-00307.1

Smith SR, Brolley J, OBrien JJ, Tartaglione CA (2007) ENSOs impact on regional U.S. Hurricane activity. J Clim 20(7):14041414. doi:10.1175/jcli4063.1

Strachan J, Vidale PL, Hodges K, Roberts M, Demory ME (2013) Investigating global tropical cyclone activity with a hierarchy of AGCMs: the role of model resolution. J Clim 26(1):133-152. doi:10.1175/JCLI-D-12-00012.1

Wang H, Long L, Kumar A, Wang W, Schemm JKE, Zhao M, Vecchi GA, Larow TE, Lim YK, Schubert SD, Shaevitz DA, Camargo SJ, Henderson N, Kim D, Jonas JA, Walsh KJE (2014) How well do global climate models simulate the variability of Atlantic tropical cyclones associated with ENSO? J Clim 27(15):56735692. doi:10.1175/JCLI-D-13-00625.1

Weatherford CL, Gray WM (1988) Typhoon structure as revealed by aircraft reconnaissance. Part I: data analysis and climatology. Mon Weather Rev 116:1032-1043

Xu G, Osborn TJ, Matthews AJ, Joshi MM (2015) Different atmospheric moisture divergence responses to extreme and moderate El Niños. Clim Dyn. doi:10.1007/s00382-015-2844-2 